\title{
Safety of Intra-articular Hyaluronic Acid Injections in Osteoarthritis: Outcomes of a Systematic Review and Meta-Analysis
}

\author{
Germain Honvo $^{1,2}\left(\right.$ ] $\cdot$ Jean-Yves Reginster ${ }^{1,2,3}\left([) \cdot\right.$ Francois Rannou $^{4,5} \cdot$ Xavier Rygaert $^{1,2} \cdot$ Anton Geerinck $^{1,2}$. \\ Véronique Rabenda $^{1,2} \cdot$ Tim McAlindon $^{6} \cdot$ Alexia Charles $^{1,2} \cdot$ Nicholas Fuggle $^{7} \cdot$ Cyrus Cooper $^{2,7,8} \cdot$ Elizabeth Curtis $^{7}$. \\ Nigel Arden ${ }^{7,9} \cdot$ Bernard Avouac $^{1} \cdot$ Olivier Bruyère $^{1,2}[$
}

(๑) The Author(s) 2019

\begin{abstract}
Background Some controversy exists regarding the safety of intra-articular hyaluronic acid (IAHA) in the management of osteoarthritis (OA).

Objective The objective of this study was to re-assess the safety profile of IAHA in patients with OA, through a comprehensive meta-analysis of randomized, placebo-controlled trials.

Methods A comprehensive literature search was undertaken in the databases MEDLINE, Cochrane Central Register of Controlled Trials (CENTRAL), and Scopus. Randomized, double-blind, placebo-controlled, parallel-group trials that assessed adverse events (AEs) with IAHA in patients with OA were eligible for inclusion. Authors and/or study sponsors were contacted to obtain the full report of AEs. The primary outcomes were overall severe and serious AEs, as well as the following MedDRA System Organ Class (SOC)-related AEs: gastrointestinal, cardiac, vascular, respiratory, nervous system, skin and subcutaneous tissue disorders, musculoskeletal, renal and urinary disorders, infections and infestations, and hypersensitivity reaction.

Results Database searches initially identified 1481 records. After exclusions according to the selection criteria, 22 studies were included in the qualitative synthesis, and nine studies having adequate data were ultimately included in the metaanalysis. From the studies excluded according to the pre-specified selection criteria, 21 with other pharmacological OA treatments permitted during the trials were a posteriori included in a parallel qualitative synthesis, from which eight studies with adequate data were finally included in a parallel meta-analysis. Since this meta-analysis was designed to assess safety, the exclusion criterion on concomitant anti-OA medication was crucial. However, due to the high number of studies that allowed mainly concomitant oral non-steroidal anti-inflammatory drugs (NSAIDs), we decided to include them in a post hoc parallel analysis in order to compare the results from the two analyses. No statistically significant difference in odds was found between IAHA and placebo for all types of SOC-related disorders, except for infections and infestations, for which significantly lower odds were found with IAHA compared with placebo, both overall (odds ratio $[\mathrm{OR}]=0.61,95 \%$ confidence interval [CI] 0.40-0.93; $\left.I^{2}=0 \%\right)$ and in studies without concomitant anti-OA medication (OR=0.49, 95\% CI 0.27-0.89). There were significant increased odds of reporting serious AEs with IAHA compared with placebo, both overall $(\mathrm{OR}=1.78$, 95\% CI 1.21-2.63; $\left.I^{2}=0 \%\right)$ and in studies with concomitant anti-OA medication (OR=1.78, 95\% CI 1.10-2.89), but not in studies without concomitant anti-OA medication $(\mathrm{OR}=1.78,95 \% \mathrm{CI} 0.92-3.47)$.

Conclusions Using the available data on studies without any concomitant anti-OA medication permitted during clinical trials, IAHA seems not to be associated with any safety issue in the management of OA. However, this evidence was associated with only a "low" to "moderate" certainty. A possible association with increased risk of serious AEs, particularly when used with concomitant OA medications, requires further investigation.
\end{abstract}

Electronic supplementary material The online version of this article (https://doi.org/10.1007/s40266-019-00657-w) contains supplementary material, which is available to authorized users.

Extended author information available on the last page of the article 


\section{Key Points}

Our meta-analysis of randomized controlled trials (RCTs) without any concomitant pharmacological osteoarthritis (OA) treatments permitted during the trials did not identify any safety issue associated with intraarticular hyaluronic acid (IAHA); however, the certainty of this new evidence was graded between "low" and "moderate".

A shortcoming in the reporting of harms-related data in manuscripts communicating outcomes of RCTs with IAHA in OA was the reason for this uncertainty, which does not allow for a definitive conclusion regarding the safety of IAHA.

Additional studies are required to further investigate the safety profile of IAHA, particularly any association with serious adverse events and long-term safety; moreover, authors of studies on IAHA are encouraged to report in a transparent way all harms data collected from RCTs in the future.

\section{Introduction}

Osteoarthritis (OA) is a chronic disorder, affecting joints such as hand, knee and hip, that causes considerable pain, increasing disability, and progressive cartilage degeneration [1]. OA occurs frequently in adults aged over 50 years and is a major cause of disability worldwide [2,3]. The incidence of $\mathrm{OA}$ is rising due to the aging population and the increase in obesity [1]. OA has a complex pathophysiology that is incompletely understood. There is no established diseasemodifying therapy for OA as yet, and hence the treatment of OA relies on a combination of pharmacological and nonpharmacological therapies that can manage the symptoms of OA, primarily pain and loss of function [4]. In practice, paracetamol, non-steroidal anti-inflammatory drugs (NSAIDs) and opioids are widely prescribed to relieve pain and improve joint function, and yet have significant toxicity [5-8]. Analgesics and NSAIDs are particularly poorly tolerated by OA patients $[9,10]$, who are frequently of advanced age, with comorbidities and are receiving polypharmacy. Intra-articular (IA) injections of corticosteroids, such as triamcinolone hexacetonide and methylprednisolone acetate, are also often prescribed. However, systemic absorption occurs following IA corticosteroid injection, which can lead to systemic adverse events (AEs), and precautions should be observed in patients with concomitant diseases, such as hypertension and diabetes mellitus [11-13].
Intra-articular hyaluronic acid (IAHA) injection presents an alternative local treatment option providing symptomatic benefit without the systemic AEs associated with IA corticosteroids. Numerous RCTs and meta-analyses have sought to assess the efficacy and safety of IAHA, with mixed results and conclusions $[14,15]$. IAHA is demonstrated to have a positive effect on pain and joint function [16]. A network meta-analysis comparing the effectiveness of pharmacological interventions for knee OA found IAHA to be the most efficacious treatment, with an effect size (ES) of 0.63 on pain (95\% credible interval [CrI] 0.39-0.88). IA placebo itself had an ES of 0.29 (95\% CrI 0.04-0.54); nonetheless a statistically significant effect for IAHA was found at 3 months ( $\mathrm{ES}=0.34,95 \% \mathrm{CrI} 0.26-0.42)$ [17]. IAHA is also demonstrated to have a longer lasting effect on pain and function compared with IA corticosteroids, lasting up to 6 months $[18,19]$.

There is also mounting data showing that multiple courses of IAHA can impact long-term outcomes, including reduction in concomitant analgesia use, and delay in the need for total knee replacement surgery [20-22]. However, despite evidence attesting to the efficacy of IAHA injections, particularly for knee OA, and the widespread use of IAHA in clinical practice, controversy still persists regarding the relative risk:benefit of IAHA, largely due to mixed reports on the safety of IAHA. Consequently, there is a lack of agreement among national and international guidelines regarding the use of IAHA for the medical management of symptomatic knee OA [4, 23-29].

Eight meta-analyses of RCTs comparing IAHA to IA placebo have evaluated the safety of IAHA [16, 17, 30-35]. A Cochrane review of 76 RCTs was unable to conclude a definitive comment on the safety of the hyaluronic acid (HA) class of products due to sample-size restrictions; however, no major safety issues were detected, and in some analyses, IAHA demonstrated similar efficacy to systemic forms of active intervention, with more local reactions but fewer systemic AEs [16]. Recent meta-analyses on the safety of different IAHA products have found that HA is generally well-tolerated, with a low incidence of AEs and without risk for serious adverse events (SAEs) [35-37]. However, a meta-analysis published in 2012 raised concerns regarding the safety of IAHA, finding an increased risk of SAEs associated with IAHA compared with sham or non-intervention control (relative risk $=1.41,95 \%$ confidence interval [CI] 1.02-1.97) [33]. Notably, almost all of those previous meta-analyses which have assessed the safety of IAHA used only published data, and it is well known that safety data are under-reported in manuscripts. Additionally, the concomitant use of oral NSAIDs during some clinical trials was not taken into account in the previous analyses. The objective of this study was therefore to reassess the safety 
of HA injections in the management of OA in a systematic review and meta-analysis of randomized, placebo-controlled trials (RCTs). In order to better estimate the safety profile of IAHA in OA, authors of the manuscripts and/or sponsors of studies were contacted to get the full report of AEs.

\section{Methods}

The protocol of this systematic review and meta-analysis has been previously registered in the PROSPERO database (registration number: CRD42017071906). The systematic review was performed in accordance with the recommendations in the Cochrane Handbook for Systematic Reviews of Interventions [38]. The findings were reported according to the Preferred Reporting Items for Systematic Reviews and Meta-Analyses (PRISMA) guidelines [39]. All the review process (study selection and risk of bias assessment) was undertaken using Covidence, the Cochrane platform for systematic reviews.

\subsection{Eligibility Criteria}

Randomized, double-blind, placebo-controlled, parallelgroup trials which have assessed AEs associated with IAHA in patients with OA were eligible for inclusion in this metaanalysis. The following studies were excluded: cross-over studies, reviews or meta-analyses, letters, comments or editorials. Studies that allowed concomitant anti-OA medications during the trial (other than rescue medication such as paracetamol or aspirin) were also excluded for the main meta-analysis, but were kept and used for a parallel analysis.

\subsection{Data Sources and Search Strategies}

A comprehensive literature search was undertaken in the databases MEDLINE (via Ovid), Cochrane Central Register of Controlled Trials (Ovid CENTRAL) and Scopus. Each database was searched from inception up until 19 June 2017. We searched for RCTs of IAHA in OA, using a combination of study design-, treatment-, and disease-specific key words and/or Medical Subject Heading (MeSH) terms. While AEs were the outcomes of interest for this study, we decided to avoid the outcome-specific key words in the search strategies because of the possibility that a study on the efficacy of a drug may have not mentioned terms related to AEs in its title, abstract or in the keywords sections. The search was limited to English and French publications and to human subjects. Detailed search strategies for MEDLINE/CENTRAL and Scopus databases are reported in the Electronic Supplementary Material (ESM1).
Two clinical trial registries, ClinicalTrials.gov (http:// clinicaltrials.gov/) and the World Health Organization's International Clinical Trials Registry Platform Search portal (http://apps.who.int/trialsearch/), were also checked for trial results that would not have been published. Finally, very recent meta-analyses were also screened for any additional relevant studies. For all studies that met the selection criteria, authors of the manuscripts and/or sponsors of studies were automatically contacted to get the full report of AEs, as far as there was any way to contact them (email, fax, telephone number or co-author email in another article).

We set up search alerts in the bibliographic databases for any new relevant RCTs that were published from 19 June 2017 until 30 September 2018.

\subsection{Study Selection and Data Extraction}

Two members of the review team (GH and XR) independently evaluated each title and abstract to exclude only obvious irrelevant studies, according to the predefined eligibility criteria. At this step, the criteria related to adverse effects were not considered for selection, as studies focusing on the efficacy of a treatment may not report data about adverse effects in the abstract; this means that all trials mentioning only the efficacy information were retrieved at this step. After this first step, the two investigators independently reviewed the full texts of the articles not excluded during the initial screening stage to determine whether the studies met all selection criteria. Those which did not meet these criteria were definitely excluded. All differences of opinion regarding the selection of articles were resolved through discussion and consensus between the two investigators (GH and XR); any persistent disagreement was solved with the intervention of another member of the review team (AG or VR). A flowchart with the number of included studies at each step was established, including the reasons for excluding studies during the full-text reading process.

The full texts of the selected studies were screened for extraction of relevant data, using a standard data extraction form. Outcome results data were independently extracted by two investigators of the review team (GH and XR). For each study, the following data were extracted: characteristics of the manuscript, characteristics of the trial, objective and design of the study, characteristics of the patients, characteristics of the disease, characteristics of the treatments, AEs (outcomes) reported during the trial, and the main conclusion of the study. The raw data (number of events in each arm of the study) were extracted for each outcome. The number of patients who experienced at least once any body system related $\mathrm{AE}$ (e.g. nervous system, gastrointestinal system) as well as specific AEs within each body system (e.g. 
headache, abdominal pain) were extracted. The total number of patients who experienced at least once any AE during the trial and the total number of patients who withdrew from the trial due to AEs were also extracted. Intention-to-treat data were only used when reported or supplied by the study authors or sponsor.

\subsection{Assessment of Risk of Bias in Included Studies}

Two members of the review team (GH and XR) independently assessed the risk of bias in each study, using the Cochrane Collaboration's tool for risk of bias assessment [38]. The following characteristics were evaluated:

- Random sequence generation: we assessed whether the allocation sequence was adequately generated.

- Allocation concealment: we assessed the method used to conceal the allocation sequence, evaluating whether the intervention allocation could have been foreseen in advance.

- Blinding of participants and personnel: we assessed the method used to blind study participants and personnel from knowledge of which intervention a participant received and whether the intended blinding was effective.

- Blinding of outcome assessment: we assessed the method used to blind outcome assessors from knowledge of which intervention a participant received and whether the intended blinding was effective.

- Incomplete outcome data: we assessed whether participants exclusions, attrition and incomplete outcome data were adequately addressed in the paper.

- Selective outcomes reporting: we checked whether there was evidence of selective reporting of AEs.

Each of these items was either categorized as "low risk of bias", "high risk of bias", or "unclear risk of bias". "Low risk of bias" or "high risk of bias" was attributed for an item when there was sufficient information in the manuscript to judge the risk of bias as "low" or "high"; otherwise, "unclear risk of bias" was attributed to the item. Disagreements were solved by discussion between the two reviewers ( $\mathrm{GH}$ and $\mathrm{XR}$ ) during a consensus meeting and involved, when necessary, another member of the review team for final decision (AG or VR).

\subsection{Outcomes of Interest}

The main System Organ Classes (SOCs) that are likely to be affected by the use of IAHA in the treatment of OA were explored in this meta-analysis. The primary outcomes of interest were MedDRA (Medical Dictionary for Regulatory Activities) SOC-related AEs: gastrointestinal disorders, cardiac disorders, vascular disorders, respiratory, thoracic and mediastinal disorders, nervous system disorders, skin and subcutaneous tissue disorders, musculoskeletal and connective tissue disorders, renal and urinary disorders, infections and infestations, as well as hypersensitivity reaction, and overall severe AEs and SAEs. Secondary outcomes were withdrawals due to AEs (i.e. the number of participants who stopped the treatment due to an $\mathrm{AE}$ ) and total number of AEs (i.e. the number of patients who experienced any AE at least once).

\subsection{Data Analysis}

Analyses were performed using STATA 14.2 software. We described harms associated with the treatment as odds ratio (OR) with 95\% CI. We computed an overall ES for each primary or secondary outcome (AE). Anticipating substantial variability among trial results (i.e. the inter-study variability), we assumed heterogeneity in the occurrence of the AEs; thus, we planned to use random-effects models for the meta-analyses. We estimated the overall effects and heterogeneity using the DerSimonian and Laird random-effects model [40]. As this method provides a biased estimate of the between-study variance with sparse events [41, 42], we also performed the meta-analyses using the restricted maximum likelihood (REML) method [43]. Indeed, we planned in the protocol to use specific methods for rare events analysis, in case it would be necessary. However, we reported only the results from the DerSimonian and Laird random-effects model, as we found no difference in the effects computed by the two methods. We preferred reporting the results from the DerSimonian and Laird method (which uses a correction factor), because it allows for displaying studies with null event on the forest plot, even if those with null event in both the intervention and control groups are excluded from the overall ES computation. On the contrary, with the REML method, these studies are not displayed on the forest plot. Additionally, the STATA command which performs the meta-analysis based on the REML method (metaan) does not have any option for displaying subgroups on the same graphic, in contrary to the DerSimonian and Laird method command (metan), which has this option ("by").

We tested heterogeneity using the Cochran's Q test. As we are performing a random-effects meta-analysis, we used the Tau-squared $\left(\mathrm{Tau}^{2}\right)$ estimate as the measure of the between-study variance. The $I$-squared $\left(I^{2}\right)$ statistic was used to quantify heterogeneity, measuring the percentage of total variation across studies due to heterogeneity [44]. In the case of substantial heterogeneity $\left(I^{2}>50 \%\right)$ [45], we pre-specified to undertake subgroup analyses, stratifying the analyses according to the following: participants' age in the intervention group, duration of OA complaint, type 
of joint treated (knee, hip), number of joints treated, origin of the HA used (avian, microbial), molecular weight of HA (high weight versus low weight), molecular structure of HA (cross-linked versus non-cross-linked), HA manufacturer, dosing regimen, number of cycles, number of injection per cycle (single versus repeated), follow-up duration, type of sham intervention used (saline versus other), use of anaesthetic before injection, ultrasound guidance for injection, industry involvement (sponsored versus non-sponsored), risk of bias in the studies (e.g. studies with low risk of bias versus all other studies).

We assessed evidence for publication bias by visual inspection of funnel plots and using the Harbord's test for funnel plot asymmetry [46], which is more suitable for dichotomous outcomes with ESs measured as OR [47] than the classical Egger's test [48]. The quality of each evidence was assessed using the GRADE approach [49], and a summary of findings table was prepared using the GRADEpro online software [50].

\subsection{Additional Analysis}

We performed additional post hoc meta-analyses, in parallel with the main meta-analysis including the studies responding to our pre-defined eligibility criteria. Indeed, studies allowing concomitant anti-OA medications, as excluded based on our eligibility criteria, as well as all studies with or without concomitant anti-OA medications, were considered separately in parallel to the primary meta-analysis. These parallel analyses were done based on the same principles announced in the data analysis section of this manuscript for the main meta-analysis. However, instead of depicting the results of the parallel analyses in separate forest plots, we preferred showing all the analyses for each outcome on the same figure, to allow for an easy comparison. Therefore, considering the rationale of this safety meta-analysis (the exclusion of studies with other anti-OA medication allowed), the parallel analyses on one single forest plot are not to be considered as subgroup analyses, as for a classical meta-analysis.

\section{Results}

\subsection{Initial Study Selection and Characteristics}

Database searches initially identified 1481 records, from which, after exclusions, 88 articles were assessed for eligibility. Of these, 67 studies were excluded for various reasons (Fig. 1). Twenty-two papers were included in the qualitative synthesis, according to our pre-specified selection criteria, and only nine studies having adequate data were ultimately included in the meta-analysis [51-72]. These studies responding to our selection criteria were without any concomitant pharmacological OA therapy, in accordance with the review protocol. Indeed, since this is a metaanalysis on the safety of IAHA, we could not include trials that had allowed another pharmacological OA treatment as concomitant medication (other than rescue medication such as paracetamol or aspirin).

Table 1 presents the characteristics of the studies included through the systematic review process (those included in the quantitative synthesis - meta-analysis - are highlighted). Almost all these studies involved patients with knee OA; only three were on patients with other joint OA (ankle OA). Most of the trials had follow-up durations varying between 25 and 29 weeks; only one trial had a follow-up duration of at least 52 weeks. Single or repeated injections of HA during a single cycle were reported, respectively, by four and 17 studies; one study was a multiple-arm study with single and repeated injections (one, three or five injections). Avian derivative or microbial derivative HA was used, but in the majority of the articles, the origin of the compound was not specified.

Of the 22 articles selected for inclusion, only seven had their published data usable for the meta-analysis; thus, the risk of selective outcome reporting was found to be "high" in more than $75 \%$ of the retrieved studies. Full safety data were received for only two studies (Table 1). Figures $2 \mathrm{a}$ and $3 \mathrm{a}$ include a summary of the risk of bias assessed for each study included in the qualitative synthesis and the risk of bias items presented as percentages across all these studies.

\subsection{Post Hoc Study Selection and Characteristics}

From the 67 studies previously excluded according to the protocol, 21 with other pharmacological OA treatments permitted were "a posteriori" included in a parallel qualitative synthesis (Fig. 1), from which eight studies with adequate data were ultimately included in a parallel meta-analysis [73-93]. In most of these studies, oral NSAIDs were permitted as rescue or concomitant medication; in a few others, opiates and steroids were allowed.

This "post hoc" decision to consider these studies with other pharmacological OA treatments in a parallel analysis was made because we were surprised by their number when compared to the number of studies without any concomitant pharmacological OA treatment allowed. We sought by so doing to compare the results from these two groups of studies, knowing that our main conclusions regarding the safety profile of IAHA will primarily be based on the results of the analyses using the studies without any concomitant pharmacological OA treatment (those responding to our prespecified selection criteria). 


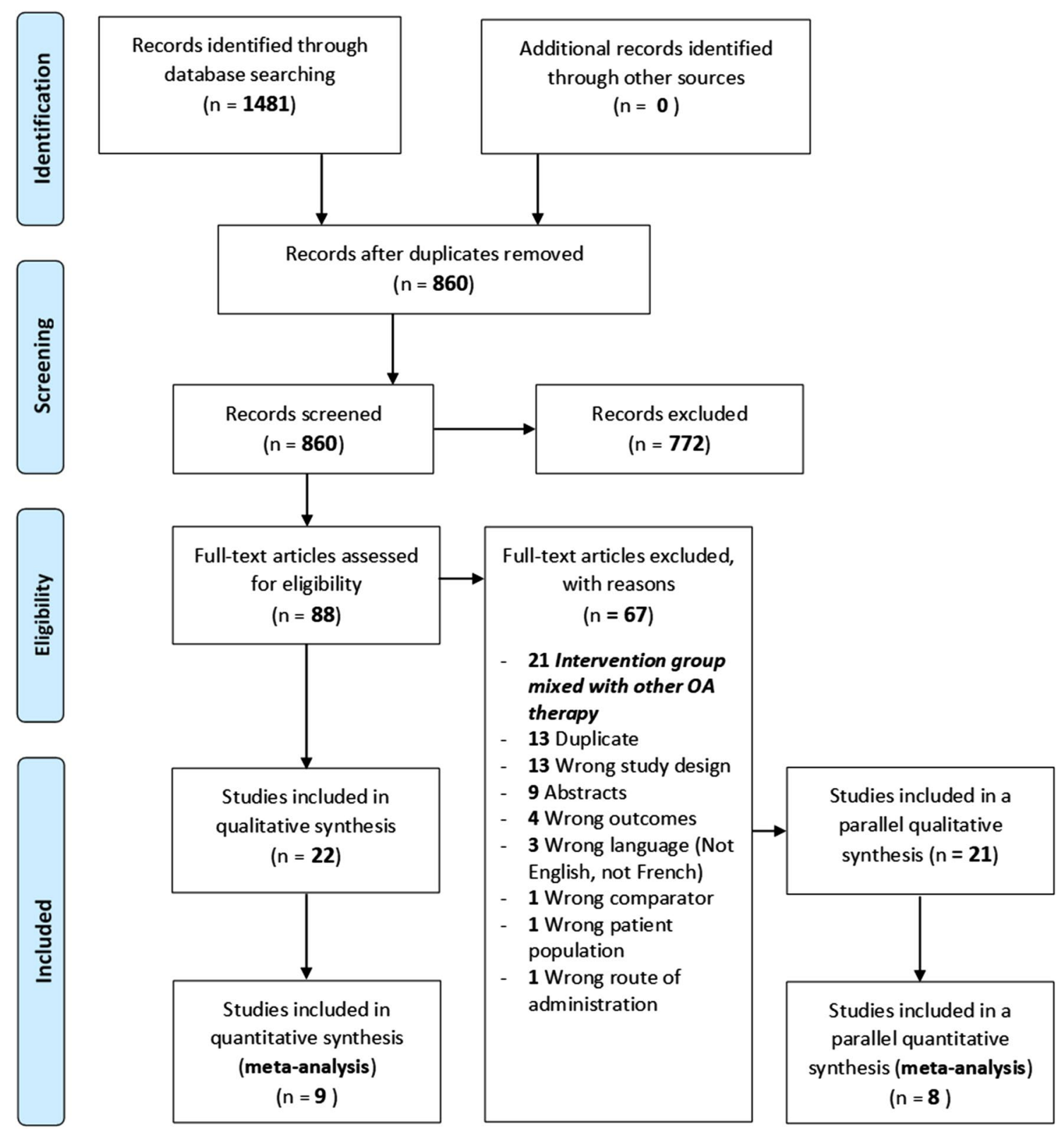

Fig. 1 Flow chart of the study. $O A$ osteoarthritis

Table 2 presents the characteristics of the studies included in the parallel qualitative synthesis (those included in the meta-analysis are highlighted). The majority of the studies retrieved for this parallel qualitative synthesis included patients with knee OA, as for the studies without any concomitant anti-OA medication; three studies included patients with hip OA, one studied patients with hand OA, and two others each included patients with OA of the glenohumeral joint and the first metatarsophalangeal joint. For most of the studies, the follow-up durations were $\leq 26$ weeks; three studies had follow-up durations of 52 weeks and one of 174 weeks.
From the 21 studies included in the parallel qualitative synthesis (i.e. with concomitant anti-OA medication), only eight, with data partially reported, were included in the parallel quantitative synthesis (meta-analysis); for the others, the published data were not usable for the meta-analysis and no adequate data were obtained from the study authors or sponsors. A "high" risk of selective outcome reporting bias was found in the majority of the studies. Figures $2 b$ and $3 b$ include a summary of the risk of bias assessed for each study included in the parallel qualitative synthesis and the risk of bias items presented as percentages across all these studies. 


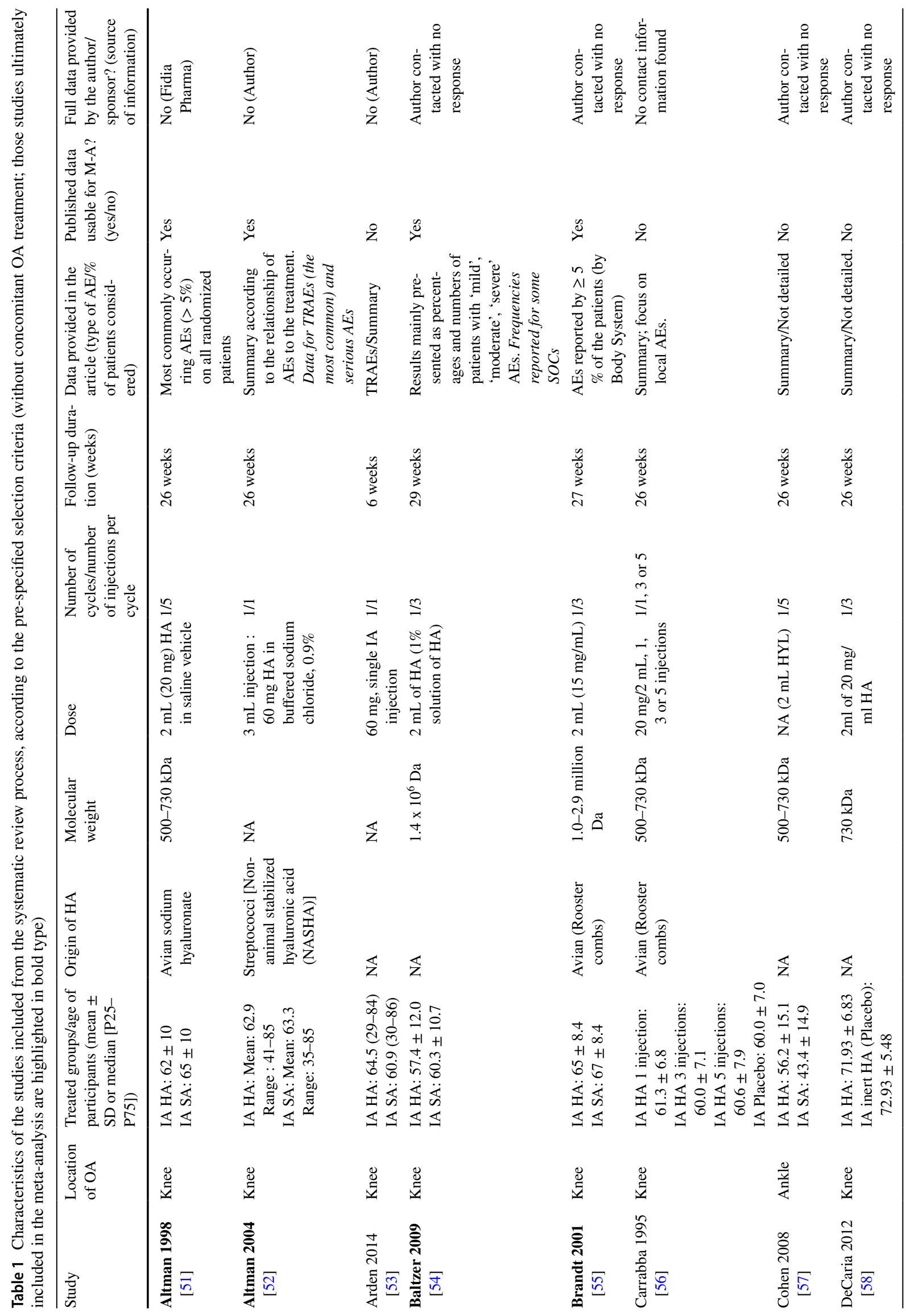




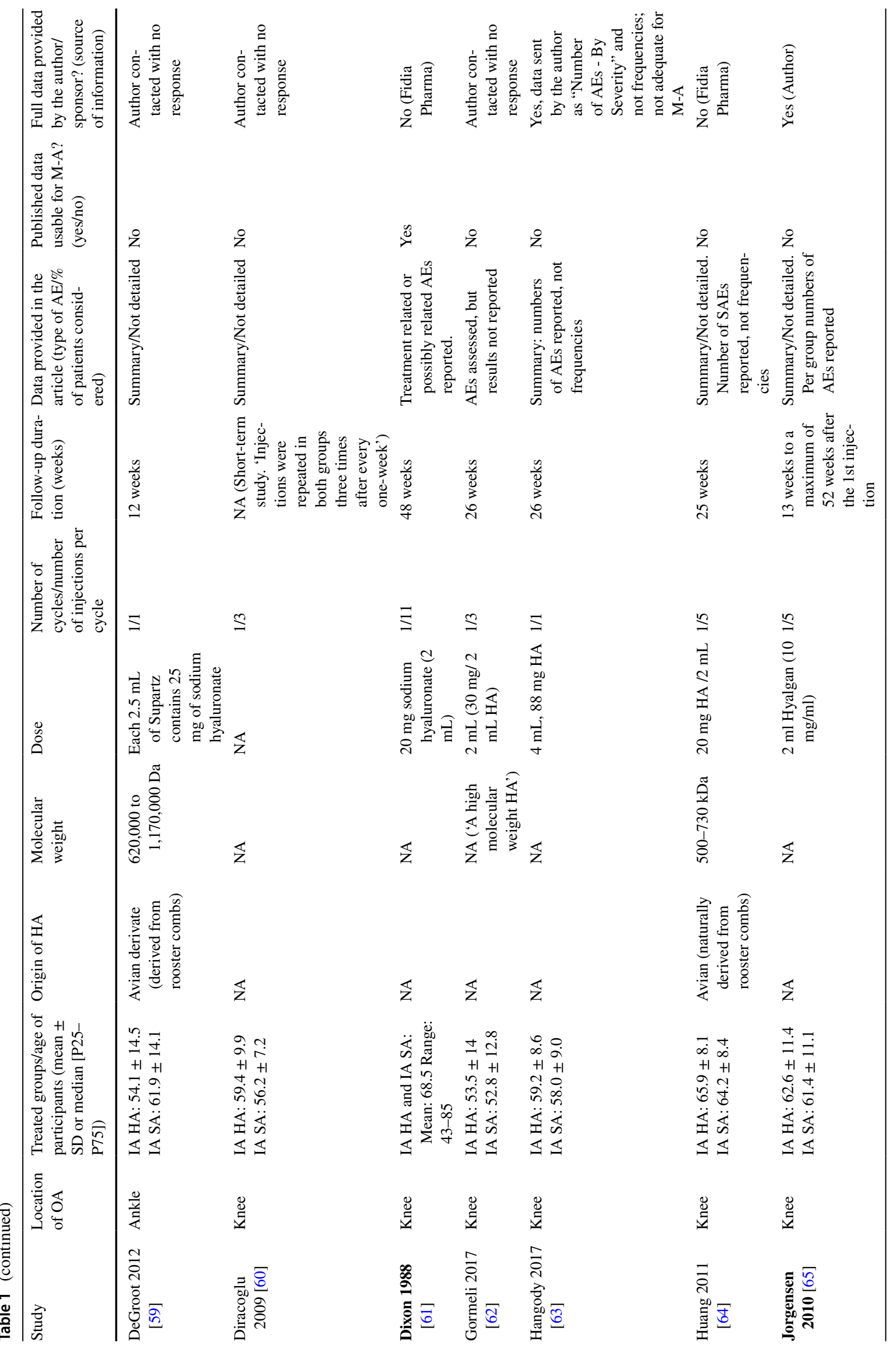




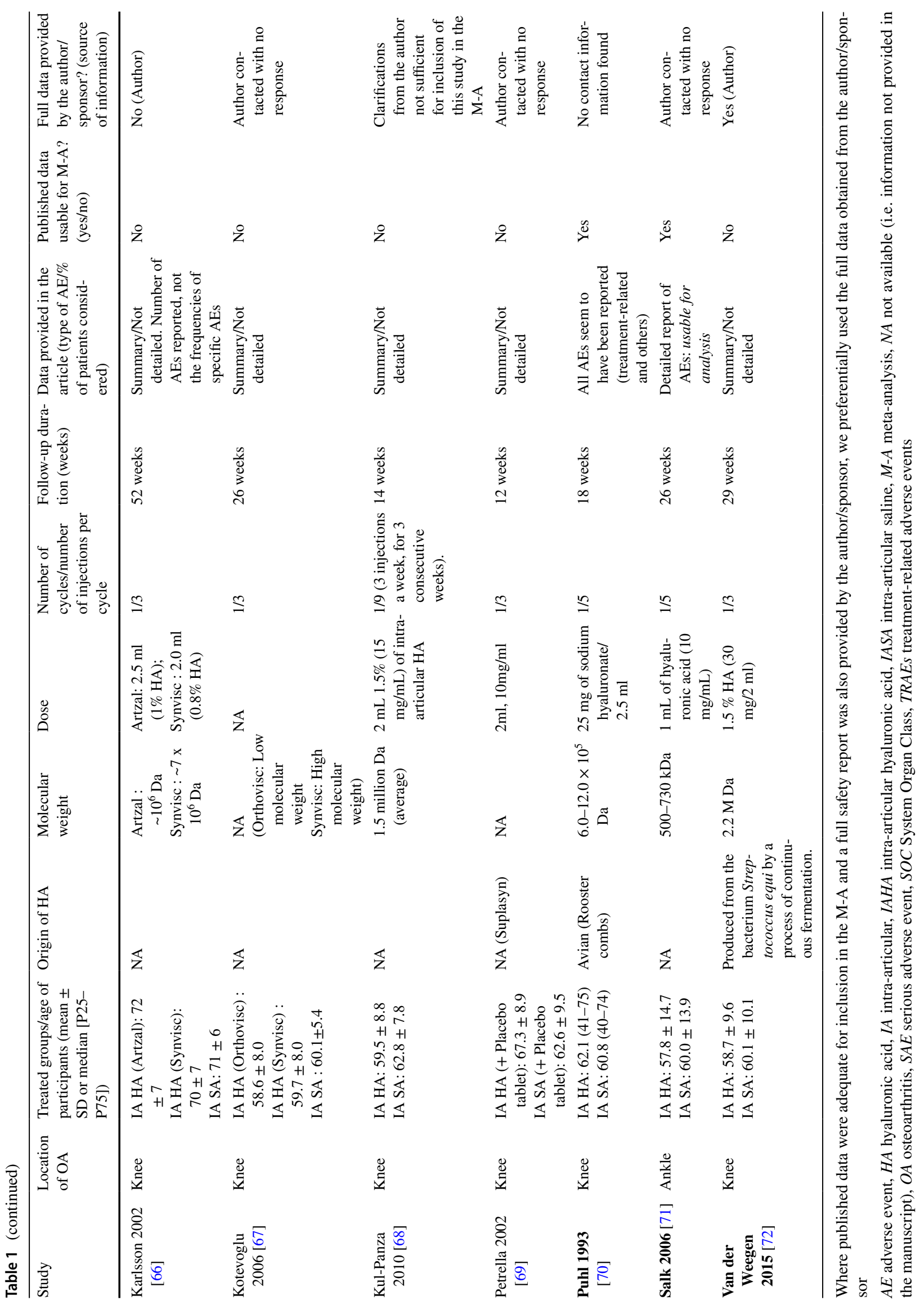


Fig. 2 a Risk of bias summary in studies without concomitant pharmacological OA treatment (studies meeting the pre-specified selection criteria): review authors' judgements about each risk of bias item for each study included in the primary qualitative synthesis. b Risk of bias summary in studies with concomitant pharmacological OA treatment (studies included in the parallel qualitative synthesis): review authors' judgements about each risk of bias item for each study included in the parallel qualitative synthesis. $O A$ osteoarthritis
(A)

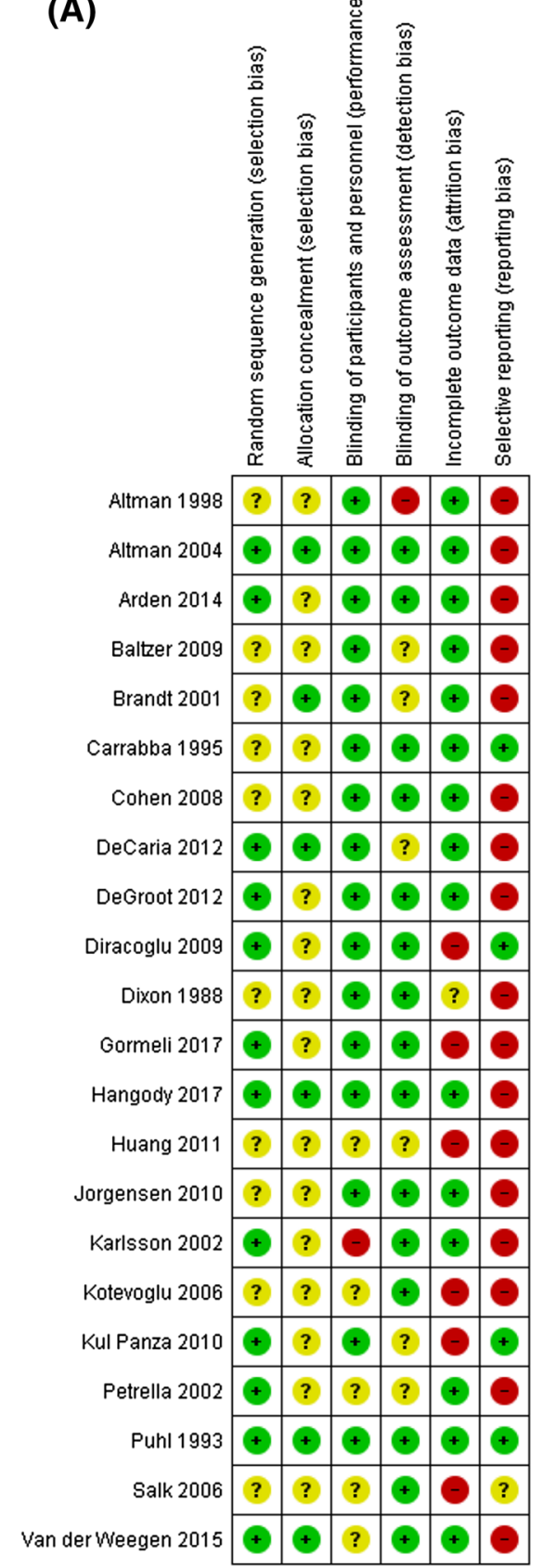

(B)
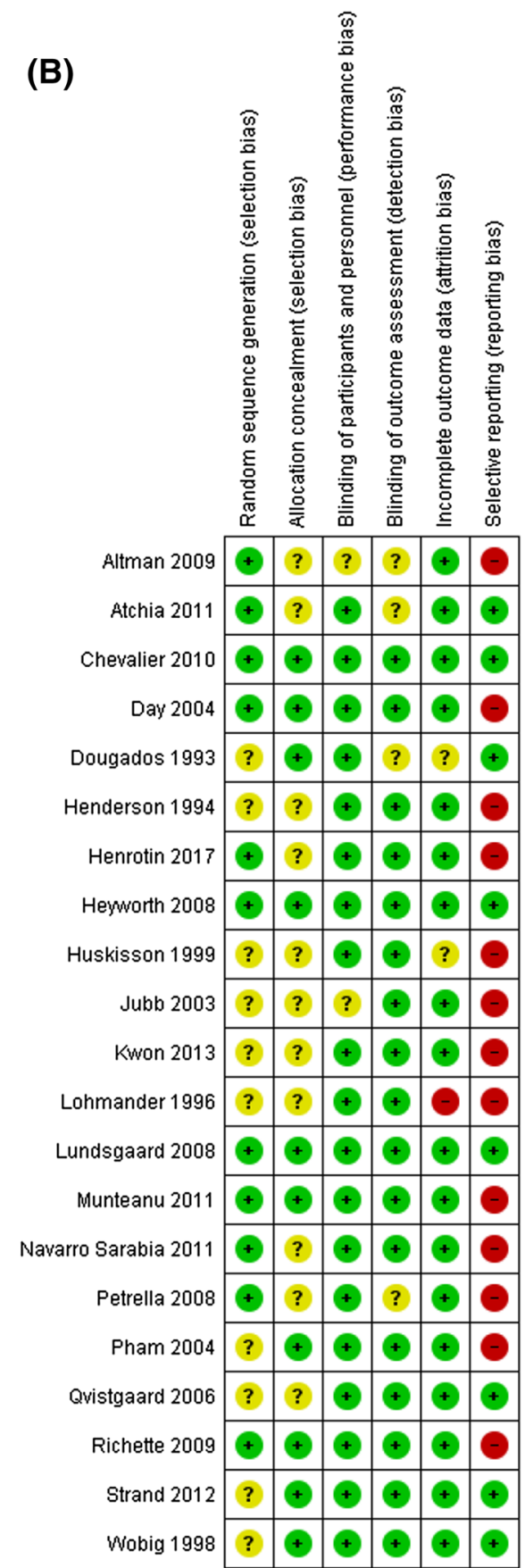

\subsection{Primary Outcomes}

Using the available data, IAHA was found to be associated with significantly lower odds of infections and infestations, overall $\left(\mathrm{OR}=0.61,95 \% \mathrm{CI} 0.40-0.93 ; I^{2}=0 \%\right)$ and in studies without any concomitant anti-OA medication allowed $\left(\mathrm{OR}=0.49,95 \%\right.$ CI $\left.0.27-0.89 ; I^{2}=0 \%\right)$ (Fig. 4). A reduced odds of infections was also found with studies that allowed concomitant OA treatment, but this did not reach statistical significance $(\mathrm{OR}=0.76,95 \% \mathrm{CI} 0.42-1.38)$. For this outcome, two main studies accounted for more than $96 \%$ of the weight in the overall analysis. Influenza, urinary tract infection and pneumonia were the most reported specific events in the placebo group, and these specific events were 
Fig. 3 a Risk of bias graph for studies without concomitant pharmacological OA treatment: review authors' judgements about each risk of bias item presented as percentages across all studies included in the primary qualitative synthesis. b Risk of bias graph for studies with concomitant pharmacological OA treatment: review authors' judgements about each risk of bias item presented as percentages across all studies included in the parallel qualitative synthesis. $O A$ osteoarthritis

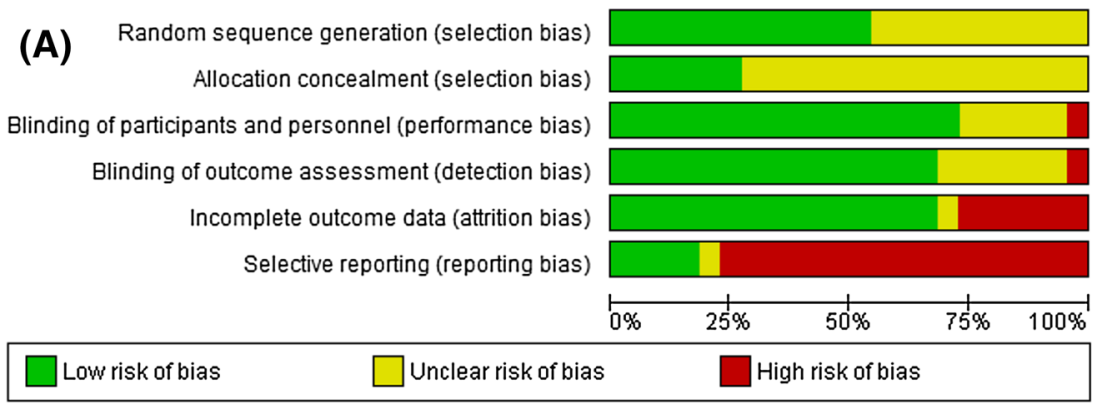

(B)

Random sequence generation (selection bias)

Allocation concealment (selection bias)

Blinding of participants and personnel (performance bias)

Blinding of outcome assessment (detection bias)

Incomplete outcome data (attrition bias)

Selective reporting (reporting bias)

$0 \%$

Unclear risk of bias

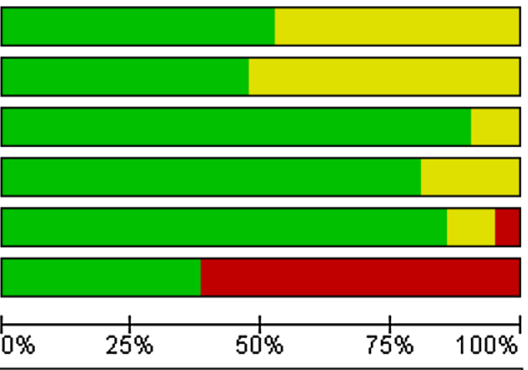

Low risk of bias

High risk of bias reported by only one study, for which the authors shared the full safety report with us 65].

No statistically significant difference was found between IAHA treatment and placebo for all other types of disorders, including gastrointestinal, cardiac, vascular, respiratory, thoracic and mediastinal, nervous system, skin and subcutaneous tissue, musculoskeletal and connective tissue, renal and urinary system disorders, and hypersensitivity reaction (see the Electronic Supplementary Material, ESM2).

There were significant increased odds of reporting SAEs in the IAHA group, both overall $(\mathrm{OR}=1.78,95 \% \mathrm{CI}$ $\left.1.21-2.63 ; I^{2}=0 \%\right)$ and in studies that allowed concomitant OA treatment $\left(\mathrm{OR}=1.78,95 \%\right.$ CI $\left.1.10-2.89 ; I^{2}=0 \%\right)$ (Fig. 5). An increased odds of SAEs was also found in studies without concomitant anti-OA treatment, but this did not reach statistical significance $(\mathrm{OR}=1.78,95 \%$ CI 0.92-3.47; $\left.I^{2}=0 \%\right)$. No statistically significant difference was found between IAHA treatment and placebo for severe AEs.

\subsection{Secondary Outcomes}

Overall, there were no more total AEs reported with IAHA versus placebo $\left(\mathrm{OR}=1.09,95 \% \mathrm{CI} 0.90-1.31 ; I^{2}=17.7 \%\right)$ and specifically without concomitant $\mathrm{OA}$ treatment allowed $\left(\mathrm{OR}=1.19,95 \% \mathrm{CI} 0.92-1.54 ; I^{2}=0 \%\right)$ and with concomitant OA treatment $\left(\mathrm{OR}=1.04,95 \%\right.$ CI $\left.0.77-1.40 ; I^{2}=0 \%\right)$ (Fig. 6).

Overall, there were significant increased odds of withdrawals due to AEs with IAHA $(\mathrm{OR}=1.62,95 \% \mathrm{CI}$
$1.04-2.51 ; I^{2}=10.0 \%$ ) and increased but not statistically significant odds of withdrawals due to AEs in studies of IAHA without concomitant anti-OA treatment $(\mathrm{OR}=1.80$, 95\% CI 0.99-3.26; $I^{2}=23.7 \%$ ) (Fig. 7).

\subsection{Assessment of Publication Bias}

Funnel plot asymmetry was visually investigated for each of the primary or secondary outcomes assessed for IAHA compared with placebo. The Harbord's test was also performed, when sufficient data were available. Whatever the outcome considered, visual inspection of funnel plots and the Harbord's test for funnel plot asymmetry (when possible) showed that there was no evidence of publication bias. The funnel plot for "total AEs" is depicted in Fig. 8; all the other funnel plots are provided as Electronic Supplementary Material (ESM3).

\subsection{GRADE Assessment of Findings}

We assessed the certainty of evidence for each primary or secondary outcome for IAHA compared with placebo, using the GRADE approach [49]. Our findings were associated with "low" to "moderate" certainty of evidence, due to serious risk of bias issues (reporting bias and/or attrition bias) across the included studies. Additionally, we found large imprecisions with some overall effect estimates because of a low number of events (null events were reported in many of the included studies and for most of the outcomes). Table 3 summarizes 


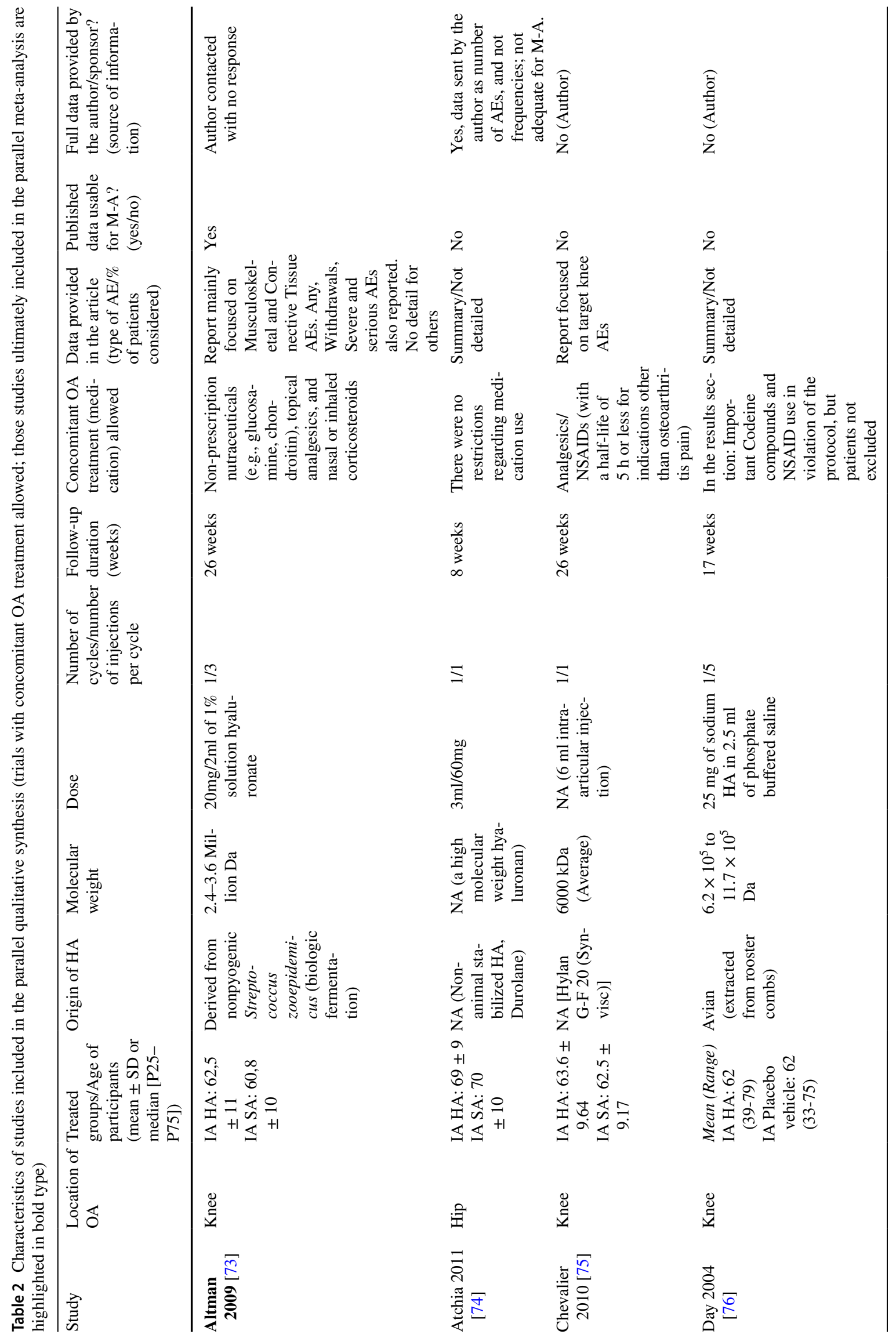




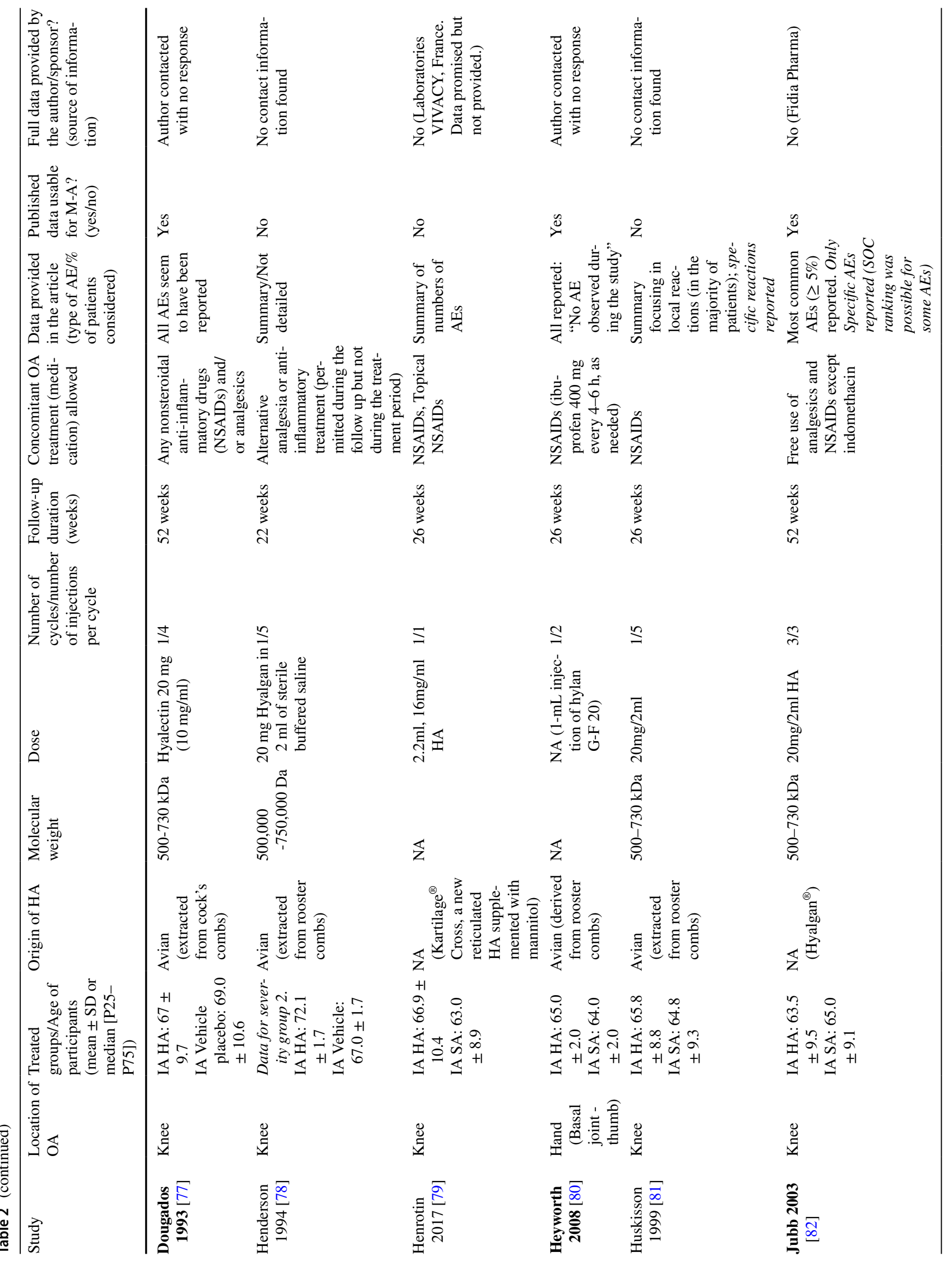




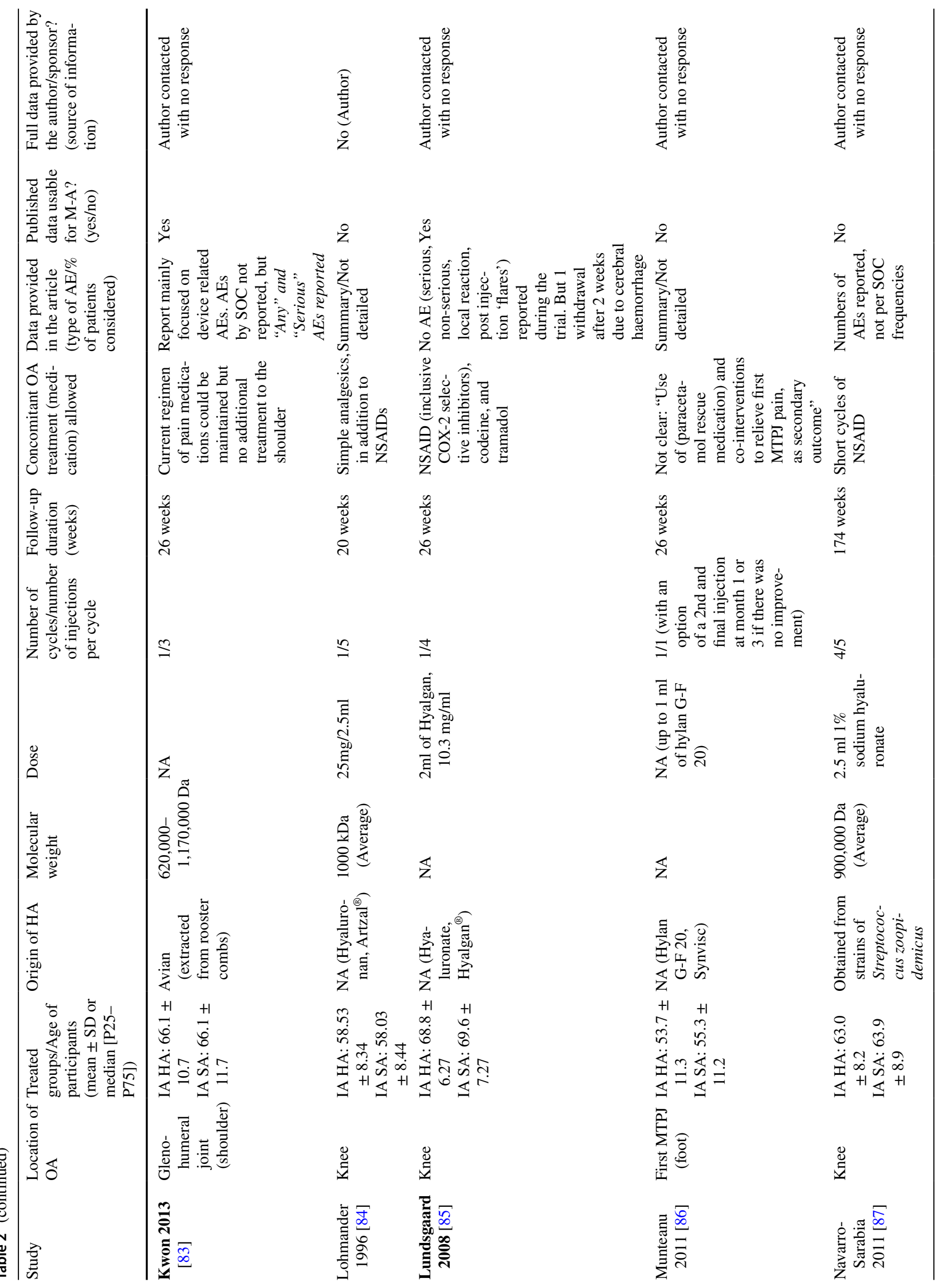




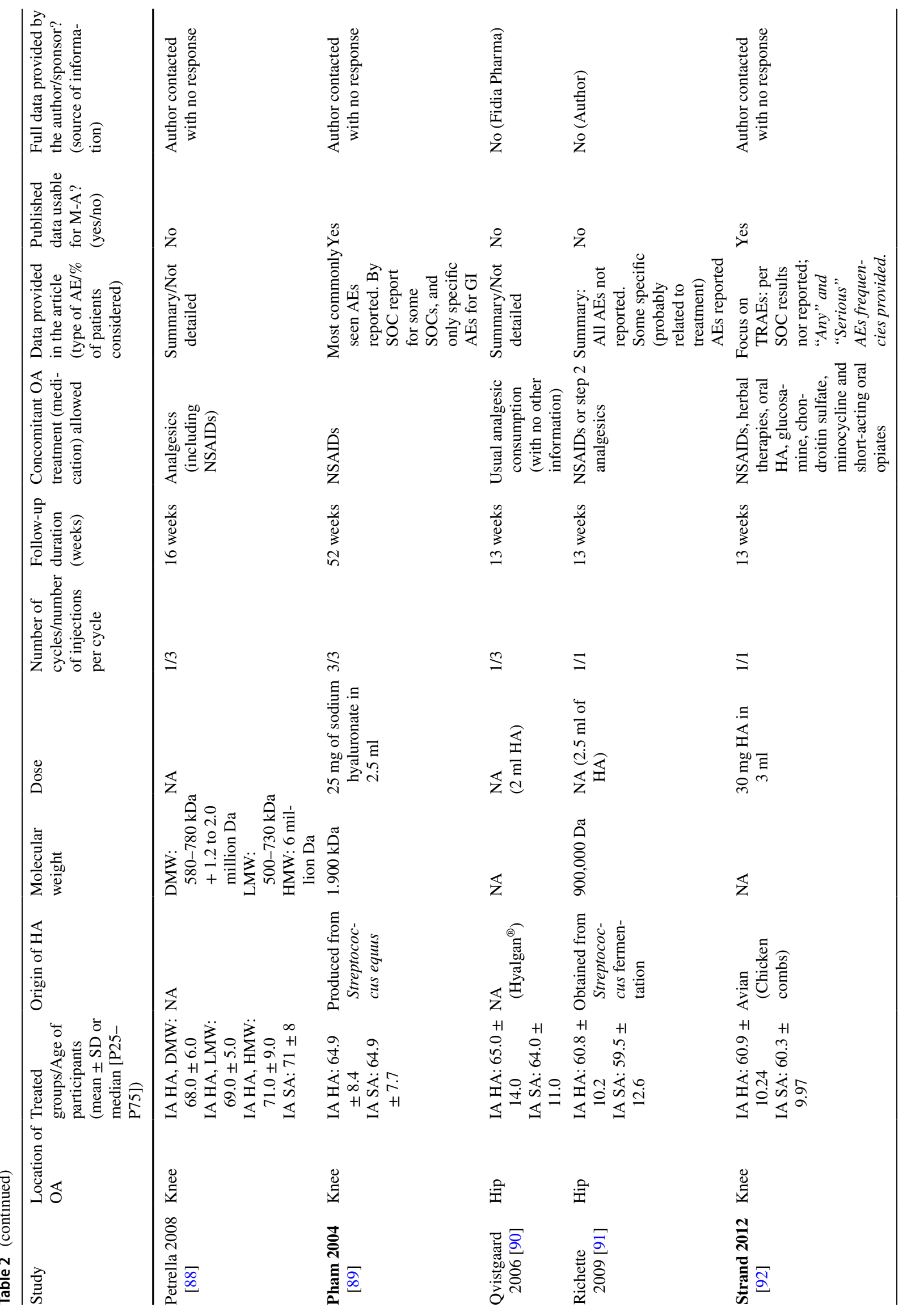




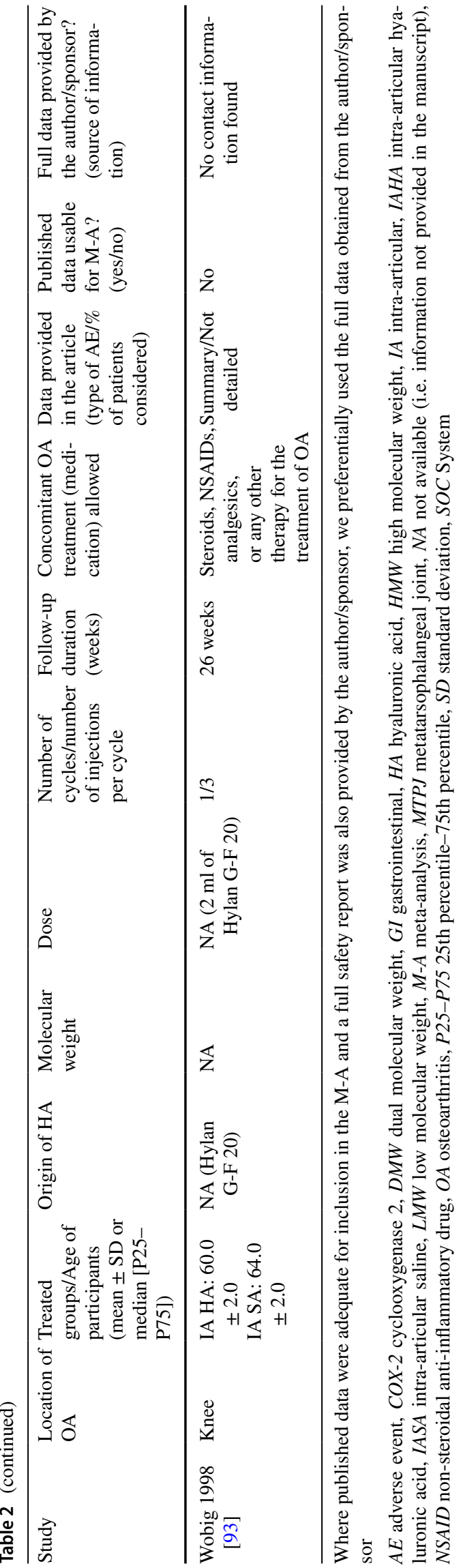

the findings on quality assessment for all outcomes assessed in this meta-analysis, showing the overall analysis data. The certainty of the evidence was the same overall and with "studies without any concomitant anti-OA medication" for almost all the outcomes, apart from "severe adverse events" for which quality was graded as "low" (in contrast to "moderate", overall) (data not shown). When considering the studies with concomitant anti-OA medication, the certainty of the evidence for "nervous system disorders" was rather "low" (in contrast to "moderate" for the other groups), and was "moderate" for "vascular disorders" and "hypersensitivity reaction" (in contrast to "low" for the other groups) (data not shown). These differences in the quality of evidence were due to differences in imprecision around the estimates.

\section{Discussion}

Overall this meta-analysis found no increased odds of total AEs with IAHA compared with placebo; this is particularly true for studies without concomitant anti-OA medication $(\mathrm{OR}=1.19,95 \%$ CI $0.92-1.54)$, but also for studies that allowed concomitant anti-OA medication. When considering only the studies which responded to our selection criteria, particularly the criteria related to the non-use of concomitant anti-OA medications during the trials, we found no statistically significant increased odds of SAEs with IAHA compared to placebo, even though there are more SAEs with IAHA $(\mathrm{OR}=1.78,95 \%$ CI 0.92-3.47).

However, we found significant increased odds of SAEs in the IAHA group versus placebo, overall and particularly in studies with concomitant OA treatment allowed $(\mathrm{OR}=1.78,95 \%$ CI 1.10-2.89). This compares with the findings of a meta-analysis from Rutjes et al., which found a $41 \%$ increased relative risk (RR) of SAEs (RR $=1.41,95 \%$ CI 1.01-1.74) [33]. In our analysis, the main studies leading to these results are the Jubb et al. 2003 study [82], the Kwon et al. 2013 study [83], and the Strand et al. 2012 study [92], respectively counting for $33.29,13.03$, and $1.87 \%$ of the total weight of all studies. In the Jubb et al. 2003 study, the free use of analgesics and NSAIDs except indomethacin was permitted during the trial [82]. In the Kwon et al. 2013 study, the usual regimen of pain medications could be maintained, but no additional treatment to the shoulder was allowed during the trial [83]. In Strand et al. [92] study, NSAIDs, herbal therapies, oral HA, glucosamine, chondroitin sulfate, minocycline and short-acting oral opiates were allowed during the trial. Oral NSAIDs are associated with an increased risk of SAEs [94], and the increased odds of SAEs reported in these studies might be due to the concomitant use of NSAIDs or other medications. These results are, however, difficult to interpret due to the paucity in the reporting of safety data for IAHA. 


\section{IAHA: Infections and infestations}

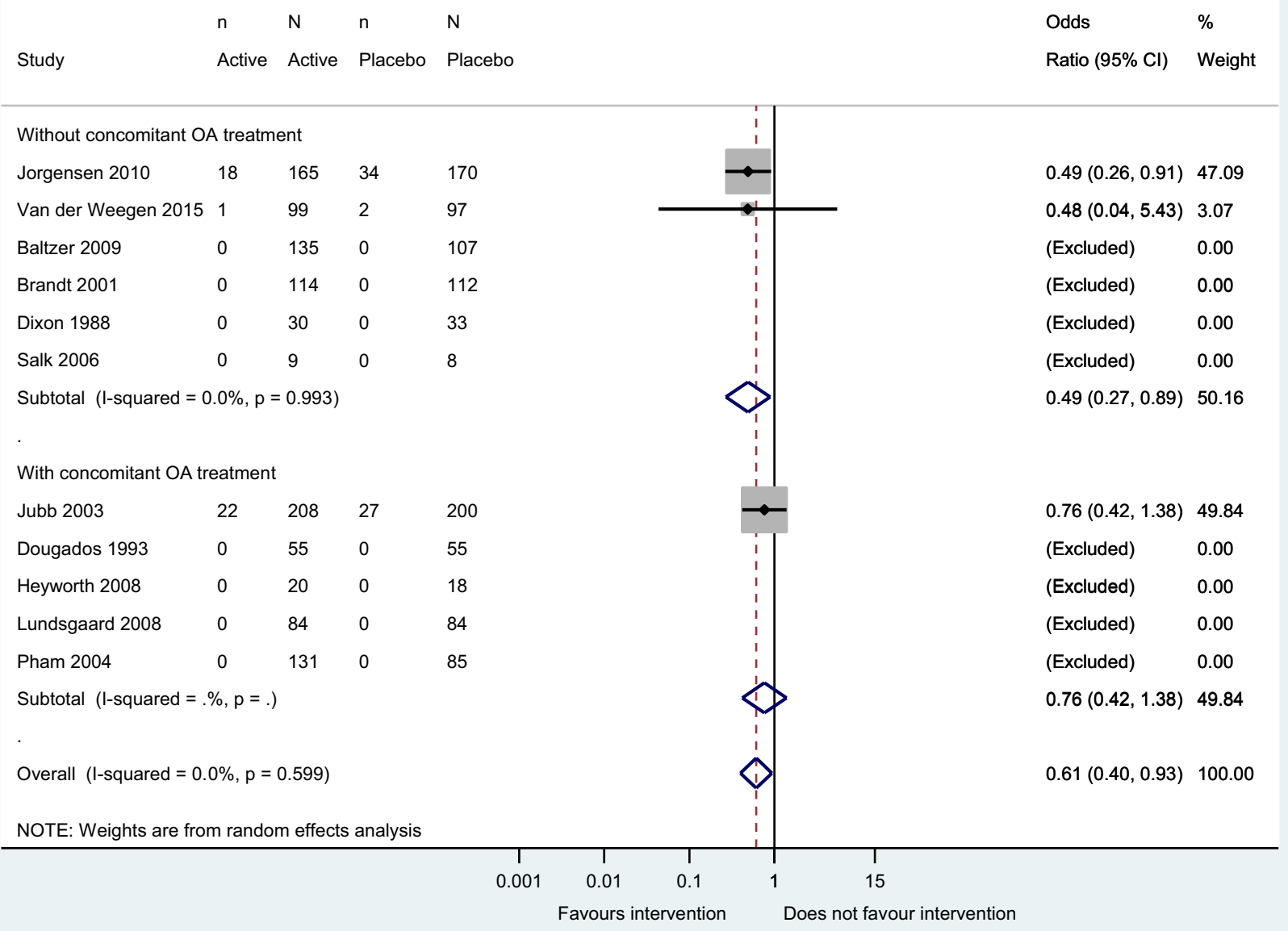

Fig. 4 Forest plot displaying the results of the meta-analyses comparing infections and infestations with IAHA versus placebo in patients with OA: analysis on studies without concomitant anti-OA medica- tion allowed, analysis on studies with concomitant anti-OA medication allowed, and overall analysis. $C I$ confidence interval, IAHA intraarticular hyaluronic acid, $O A$ osteoarthritis
Like the Rutjes meta-analysis [33], our analysis includes data from the trial of Strand et al. of a cross-linked HA product (Gel-200) [92]. While the trial found a similar rate of AEs between IAHA and saline placebo, eight cases of SAEs were reported in the Gel-200 group, all judged unrelated to study treatment, including five cancers diagnosed soon after treatment administration. The biological plausibility of a link between IAHA and the SAEs reported has been questioned in the literature $[95,96]$, and there is no pre-clinical data to suggest any carcinogenicity with Gel-200 [92]. In contrast with our meta-analysis, which includes all types of HA, two meta-analyses of US-approved HA products have found no statistically significant differences between IAHA and IA placebo for any safety outcomes [34, 35].

We found a significant increase in odds of withdrawals due to AEs associated with IAHA overall $(+62 \%$; $95 \%$ CI
1.04-2.51), which was particularly high in studies of IAHA without concomitant anti-OA treatment $(+80 \%)$ although this result did not reach significance (95\% CI 0.99-3.26). This is in agreement with the Rutjes meta-analysis, which did not make any difference in the studies regarding to the use of concomitant anti-OA medications and also found an overall increased risk of dropouts due to AEs $(\mathrm{RR}=1.33$; 95\% CI 1.01-1.74) [33].

We observed a high rate of selective outcome reporting in the studies included in this meta-analysis; over $50 \%$ of studies did not adequately report safety data (Fig. 3a, b). Only two authors (Jorgensen et al. [65]; van der Weegen et al. [72]) shared full safety reports with us for the purpose of this meta-analysis, and no full safety report was obtained for any of the studies with concomitant anti-OA medications. This may have led to a very large underestimation of 


\section{Intra-articular hyaluronic acid: Serious adverse events}

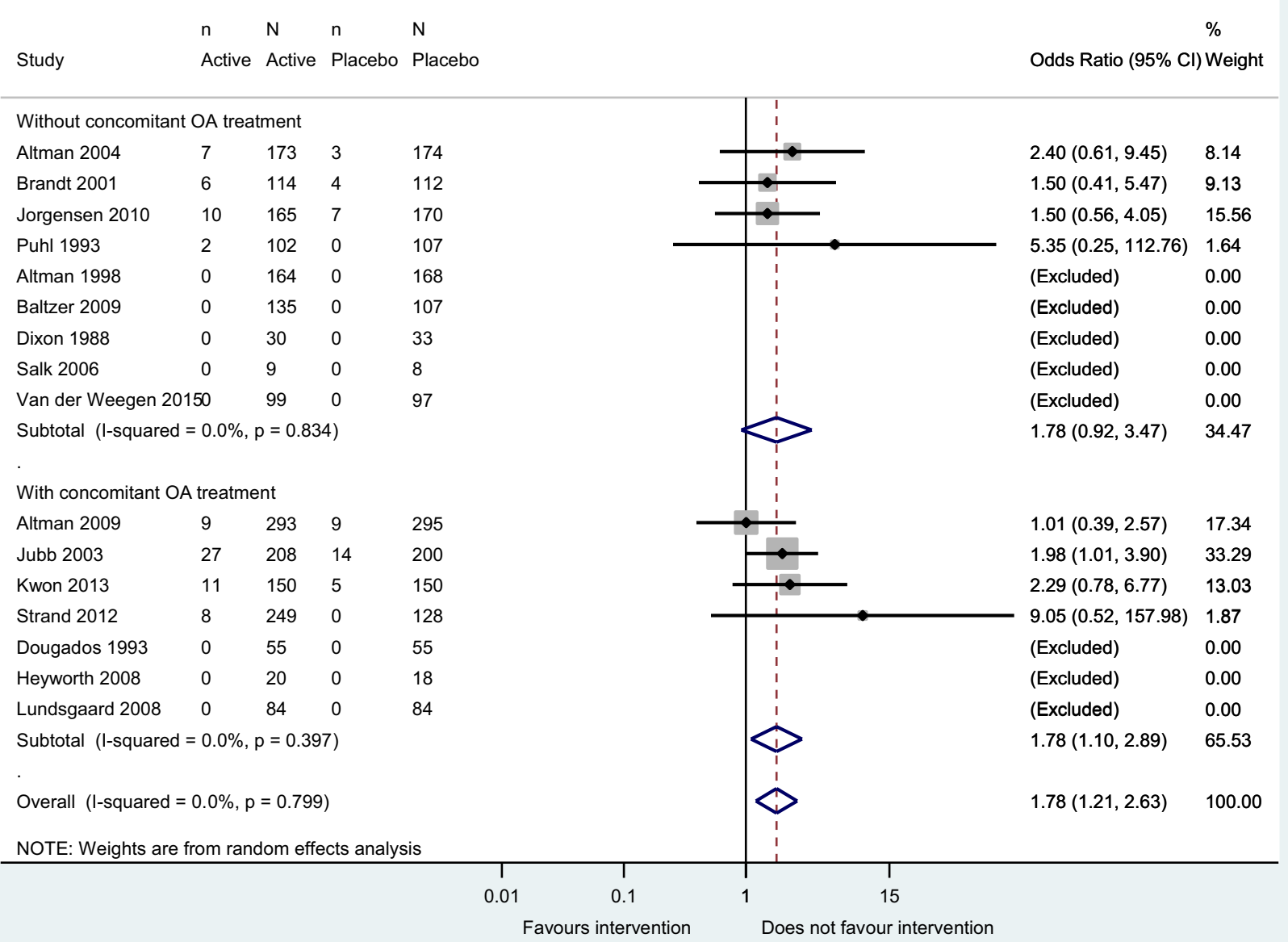

Fig. 5 Forest plot displaying the results of the meta-analyses comparing serious adverse events with intra-articular hyaluronic acid versus placebo in patients with OA: overall analysis and analyses on studies with and without concomitant anti-OA medication allowed. $C I$ confidence interval, $O A$ osteoarthritis

95\% CI 0.40-0.93). This was also the case in the group of studies without concomitant pharmacological OA treatment $(\mathrm{OR}=0.49,95 \%$ CI $0.27-0.89)$. This has significantly been reported by a single study (Jorgensen et al. [65]), for which the author provided us with the full safety report and in which the main events reported were influenza, urinary tract infection, and pneumonia. This study counted for almost half $(47.09 \%)$ of the weight of studies included in the overall analysis. A second study (with concomitant anti-OA medication) representing $49.84 \%$ of the overall studies weight also reported fewer infections in the IAHA group compared with placebo, but the difference in odds was not statistically significant (Jubb et al. [82]). A few in vitro studies suggest an anti-microbial effect of $\mathrm{HA}$ at levels of $1 \mathrm{mg} / \mathrm{mL}$ 


\section{Intra-articular hyaluronic acid: Any adverse event}

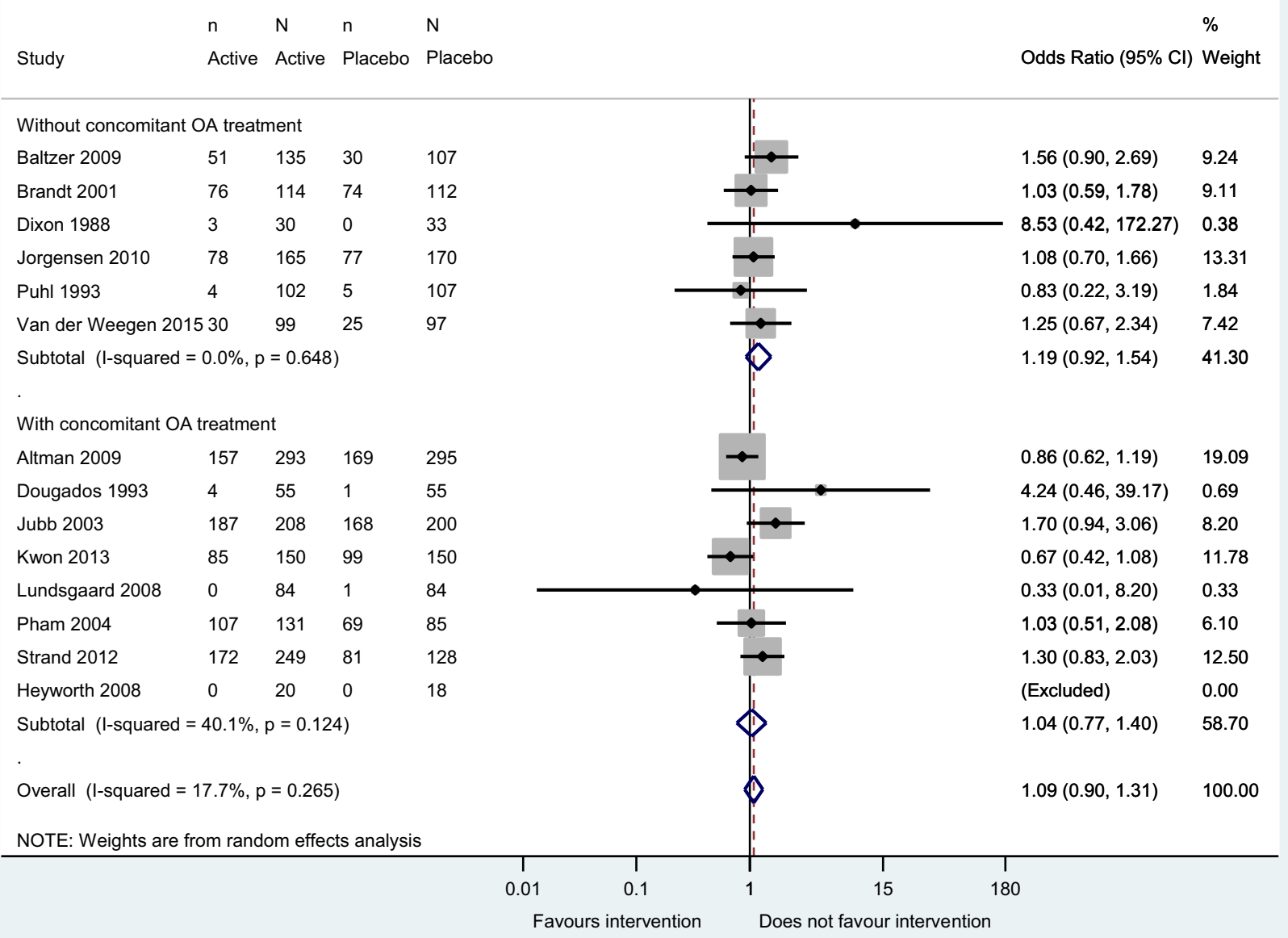

Fig. 6 Forest plot displaying the results of the meta-analyses comparing total adverse events with intra-articular hyaluronic acid versus placebo in patients with OA: overall analysis and analyses on studies with and without concomitant anti-OA medication allowed. $C I$ confidence interval, $O A$ osteoarthritis

meta-analyses by giving access to full safety reports from the studies. Additionally, long-term safety studies are warranted as IAHA is often given as repeated courses of three to five injections; in fact, for most of the studies included in this systematic review, the follow-up durations varied from 8 to 26 weeks (Tables 1,2). Multiple courses of IAHA are shown to be safe over 6-18 months from a postmarketing registry of one HA product (Supartz), with an overall AE rate of 0.008 (95\% CI 0.001-0.055) [37]. The majority of people who reported an AE did so in the first injection series, of which $85 \%$ were injection site reactions. Conversely, an increased frequency of acute local reactions has been reported with multiple cycles of IAHA [99], while one review reports that the safety remains unchanged with 


\section{IAHA: Withdrawals due to adverse events}

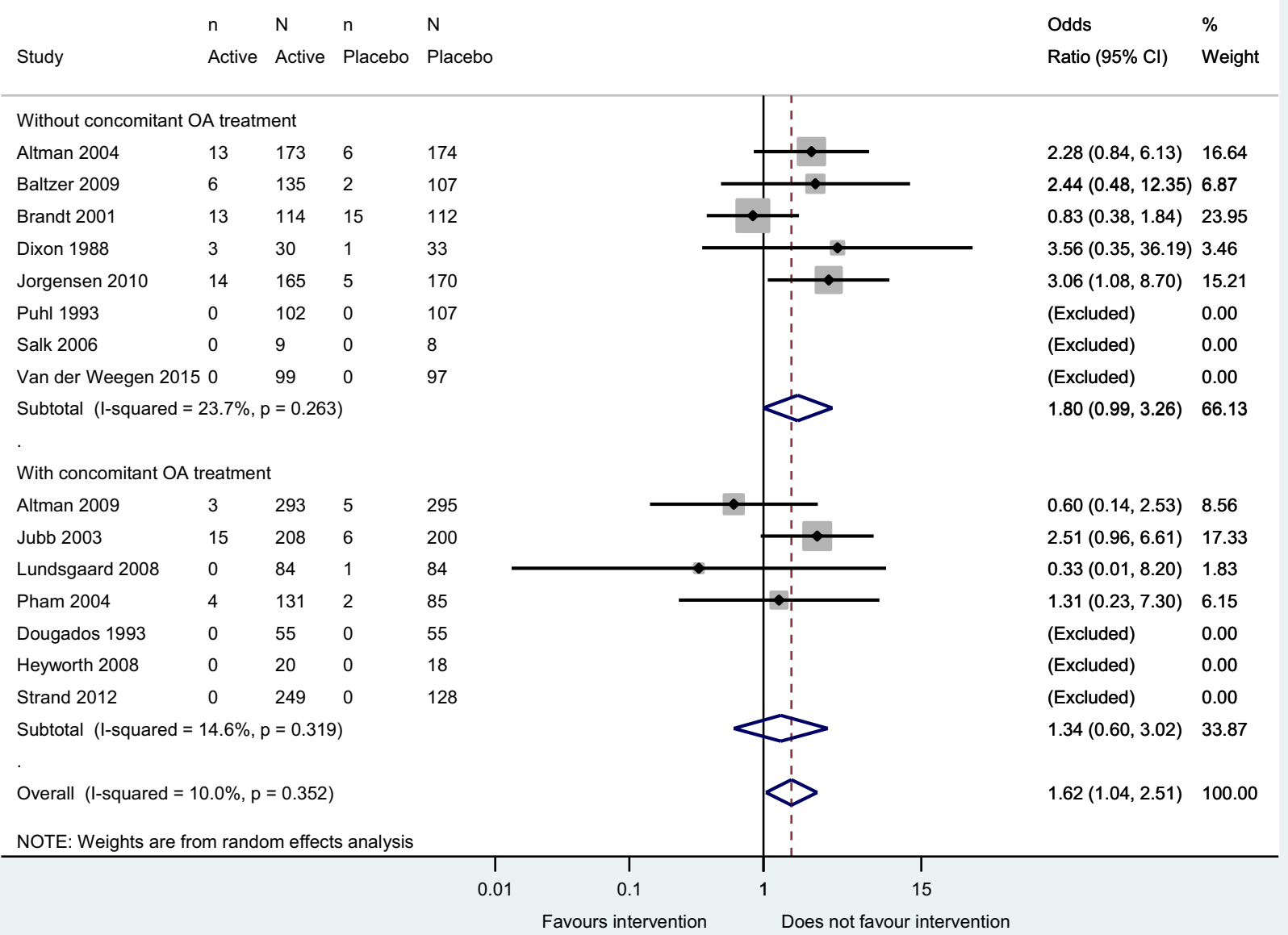

Fig. 7 Forest plot displaying the results of the meta-analyses comparing withdrawals due to adverse events with IAHA versus placebo in patients with OA: overall analysis and analyses on studies with and

multiple courses of treatment [100]. Additionally, it has been reported that, in comparison with other pharmacological treatments for OA, IAHA appears to be associated with fewer systemic AEs than paracetamol or NSAIDs, but more local reactions, and a lower rate of withdrawals due to AEs $[16,17]$. However, all this evidence deserves further investigation; transparency in the reporting of harms collected during clinical trials on IAHA will assist significantly in clarifying the safety profile of IAHA, for which the onus is without concomitant anti-OA medication allowed. $C I$ confidence interval, IAHA intra-articular hyaluronic acid, $O A$ osteoarthritis

on pharmaceutical companies developing HA for patients with OA.

\subsection{Strengths}

Only RCTs versus placebo were included, and hence, the real effect is not underestimated. Many SOCs were investigated; not only "total AEs", "SAEs" or "skin AEs", as reported in many previous meta-analyses. To avoid double counting of AEs, for each SOC, we considered the number of patients 


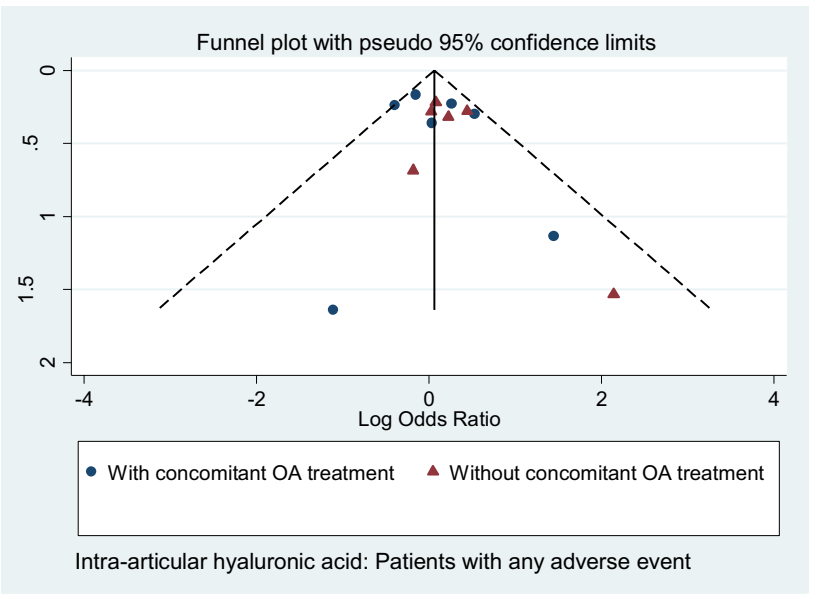

Harbord's test: $p=0.26$

Fig. 8 Assessment of publication bias: funnel plot using data for the meta-analysis comparing total adverse events with intra-articular hyaluronic acid versus placebo in patients with OA. Harbord's test: $p=0.26$. $O A$ osteoarthritis, $O R$ odds ratio

who experienced at least once any related AE. For total AEs (any AEs), we considered the number of patients who experienced, at least once, any AE during the study.

\section{Limitations}

Many studies identified that met the inclusion criteria did not provide AE data suitable for inclusion in the meta-analysis and the authors/sponsors did not provide us with the full safety data. As a consequence, subgroup analyses were not possible, which would have helped to explore any subgroup differences in the occurrence of SAEs with the studies included in the parallel post hoc meta-analysis (e.g. analyses by HA subtypes).

\section{Conclusions}

Paucity in the reporting of AEs does not allow for a definitive conclusion regarding the safety profile of IAHA in OA. Based on the available data regarding studies without concomitant anti-OA medications, IAHA seems not to be associated with any safety issue in the management of $\mathrm{OA}$; however, the certainty of this evidence was graded between "low" and "moderate". The SAEs found in some other metaanalyses as well as in our parallel post hoc analysis might be due to the allowance for concomitant use of oral NSAIDs during some trials or to other factors, but this deserves further investigation. Overall, further investigation on the safety of IAHA is warranted, in particular, greater contribution from pharmaceutical companies in providing full safety reports for future meta-analyses. Authors of manuscripts on future trials on IAHA are also encouraged to report harms collected during these trials in a transparent way. Further studies are also required to determine the long-term safety of IAHA.

This paper is written on behalf of the European Society for Clinical and Economic Aspects of Osteoporosis, Osteoarthritis and Musculoskeletal Diseases (ESCEO) Working Group on the safety of anti-osteoarthritis medications: Nasser Al-Daghri, Nigel Arden, Bernard Avouac, Olivier Bruyère, Roland Chapurlat, Philip Conaghan, Cyrus Cooper, Elizabeth Curtis, Elaine Dennison, Nicholas Fuggle, Gabriel Herrero-Beaumont, Germain Honvo, Margreet Kloppenburg, Stefania Maggi, Tim McAlindon, Alberto Migliore, Ouafa Mkinsi, François Rannou, Jean-Yves Reginster, René Rizzoli, Roland Roth, Thierry Thomas, Daniel Uebelhart, and Nicola Veronese. The authors of this article express their most sincere gratitude to Doctors Kristian StengaardPedersen and Walter van der Weegen, who kindly accepted to collaborate with this project by sharing the raw safety data from their studies. We acknowledge the assistance and advice of Nancy Durieux and Frédéric de Lemos Esteves from the Library of Life Sciences, University of Liège, Belgium, in the preparation of the search strategies for the systematic review. We thank them very sincerely for their contribution to one of the most important parts of this research. The authors would also like to express their most sincere gratitude to Dr Lisa Buttle, PhD, of Medscript Ltd, for her invaluable assistance with the manuscript preparation. Dr Lisa Buttle was entirely funded by the ESCEO asbl, Belgium. 


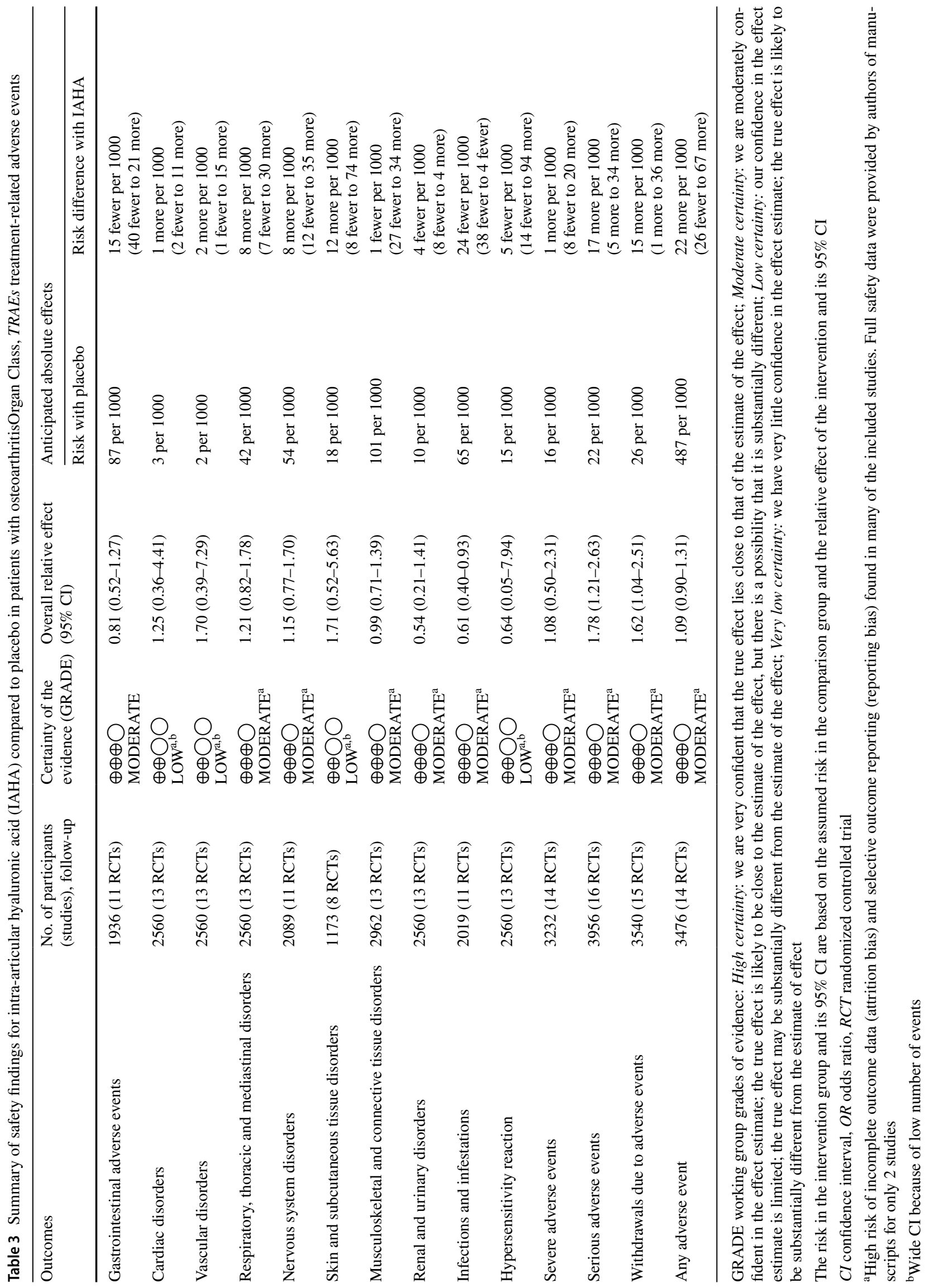




\section{Compliance with Ethical Standards}

All authors meet the International Committee of Medical Journal Editors (ICMJE) criteria for authorship for this manuscript, take responsibility for the integrity of the work as a whole, and have given final approval to the version to be published.

Funding G. Honvo was funded by the ESCEO, a Belgian not-for-profit organization. The ESCEO Working Group was entirely funded by the ESCEO. The ESCEO receives unrestricted educational grants, to support its educational and scientific activities, from non-governmental organizations, not-for-profit organizations, non-commercial and corporate partners. The choice of topics, participants, content and agenda of the working groups as well as the writing, editing, submission and reviewing of the manuscript are under the sole responsibility of the ESCEO, without any influence from third parties.

Declaration of interests $\mathrm{O}$. Bruyère reports grants from Biophytis, IBSA, MEDA, Servier, SMB, and Theramex, outside of the submitted work. C. Cooper reports personal fees from Alliance for Better Bone Health, Amgen, Eli Lilly, GSK, Medtronic, Merck, Novartis, Pfizer, Roche, Servier, Takeda and UCB, outside of the submitted work. J.-Y. Reginster reports grants from IBSA-Genevrier, Mylan, CNIEL, and Radius Health (through institution); consulting fees from IBSAGenevrier, Mylan, CNIEL, Radius Health, and Pierre Fabre; fees for participation in review activities from IBSA-Genevrier, Mylan, CNIEL, Radius Health, and Teva; payment for lectures from AgNovos, CERIN, CNIEL, Dairy Research Council (DRC), Echolight, IBSA-Genevrier, Mylan, Pfizer Consumer Health, Teva, and Theramex, outside of the submitted work. B. Avouac reports consulting fees from Novartis, BMS, Roche, Janssen Cilag, Expanscience, and IRIS, and fees for participating in research activities from Sanofi, Amgen, Takeda, Allegan, AbbVie, Vertex, AstraZeneca, Ipsen, Leadiant, Otsuka, Jazz, Leo and Alexion, outside of the submitted work. E. Curtis reports lecture fees and travel support from Eli Lilly, Pfizer and UCB, outside of the submitted work. N. Fuggle reports travel support from Eli Lilly and Pfizer, outside of the submitted work. N. Arden reports personal fees from Bioventus, Flexion, Merck, Pfizer/Lilly, Regeneron, Smith \& Nephew, and Freshfields Bruckhaus Deringer and grants from Bioiberica and Merck, outside the submitted work. F. Rannou reports grants from APHP, INSERM, University Paris Descartes, and Arthritis (Road Network), and consulting fees from Pierre Fabre, Expanscience, Thuasne, Servier, Genevrier, Sanofi Aventis, and Genzyme, outside of the submitted work. T. McAlindon reports fees for participation in review activities from Pfizer and fees for consulting activities with Flexion, Samumed, Sanofi, Visgo, Roche, Astellas, Pfizer, Seikayaku, Regeneron, and Anika, outside of the submitted work. G. Honvo, X. Rygaert, A. Geerinck, V. Rabenda and A. Charles report nothing to disclose.

Open Access This article is distributed under the terms of the Creative Commons Attribution-NonCommercial 4.0 International License (http://creativecommons.org/licenses/by-nc/4.0/), which permits any noncommercial use, distribution, and reproduction in any medium, provided you give appropriate credit to the original author(s) and the source, provide a link to the Creative Commons license, and indicate if changes were made.

\section{References}

1. Bijlsma JW, Berenbaum F, Lafeber FP. Osteoarthritis: an update with relevance for clinical practice. Lancet. 2011;377(9783):2115-26. https://doi.org/10.1016/S0140 $-6736(11) 60243-2$.
2. Pereira D, Peleteiro B, Araujo J, Branco J, Santos RA, Ramos E. The effect of osteoarthritis definition on prevalence and incidence estimates: a systematic review. Osteoarthr Cartil. 2011;19(11):1270-85. https://doi.org/10.1016/j. joca.2011.08.009.

3. Vos T, Flaxman AD, Naghavi M, Lozano R, Michaud C, Ezzati $\mathrm{M}$, et al. Years lived with disability (YLDs) for 1160 sequelae of 289 diseases and injuries 1990-2010: a systematic analysis for the Global Burden of Disease Study 2010. Lancet. 2012;380(9859):2163-96. https://doi.org/10.1016/s0140 $-6736(12) 61729-2$.

4. Bruyere O, Cooper C, Pelletier JP, Branco J, Brandi ML, Guillemin $\mathrm{F}$, et al. An algorithm recommendation for the management of knee osteoarthritis in Europe and internationally: a report from a task force of the European Society for Clinical and Economic Aspects of Osteoporosis and Osteoarthritis (ESCEO). Semin Arthritis Rheum. 2014;44(3):253-63. https://doi.org/10.1016/j. semarthrit.2014.05.014.

5. Roberts E, Delgado Nunes V, Buckner S, Latchem S, Constanti M, Miller P, et al. Paracetamol: not as safe as we thought? A systematic literature review of observational studies. Ann Rheum Dis. 2016;75(3):552-9. https://doi.org/10.1136/annrheumdi s-2014-206914.

6. Coxib and traditional NSAID Trialists' (CNT) Collaboration, Bhala N, Emberson J, Merhi A, Abramson S, Arber N, et al. Vascular and upper gastrointestinal effects of non-steroidal antiinflammatory drugs: meta-analyses of individual participant data from randomised trials. Lancet. 2013;382(9894):769-79. https:// doi.org/10.1016/s0140-6736(13)60900-9.

7. Castellsague J, Riera-Guardia N, Calingaert B, Varas-Lorenzo C, Fourrier-Reglat A, Nicotra F, et al. Individual NSAIDs and upper gastrointestinal complications: a systematic review and meta-analysis of observational studies (the SOS project). Drug Saf. 2012;35(12):1127-46. https://doi.org/10.2165/11633470000000000-00000.

8. da Costa BR, Nuesch E, Kasteler R, Husni E, Welch V, Rutjes $\mathrm{AW}$, et al. Oral or transdermal opioids for osteoarthritis of the knee or hip. Cochrane Database Syst Rev. 2014;9:CD003115. https://doi.org/10.1002/14651858.cd003115.pub4.

9. Megale RZ, Deveza LA, Blyth FM, Naganathan V, Ferreira PH, McLachlan AJ, et al. Efficacy and safety of oral and transdermal opioid analgesics for musculoskeletal pain in older adults: a systematic review of randomized, placebo-controlled trials. J Pain. 2017. https://doi.org/10.1016/j.jpain.2017.12.001.

10. Wehling M. Non-steroidal anti-inflammatory drug use in chronic pain conditions with special emphasis on the elderly and patients with relevant comorbidities: management and mitigation of risks and adverse effects. Eur J Clin Pharmacol. 2014;70(10):1159-72. https://doi.org/10.1007/s00228-014-1734-6.

11. Axelrod L. Glucocorticoids. In: Kelley WN, Harris EDJ, Sledge $\mathrm{CB}$, editors. Textbook of rheumatology. 4 th ed. Philadelphia: WB Saunders; 1993. p. 779-96.

12. Younes M, Neffati F, Touzi M, Hassen-Zrour S, Fendri Y, Bejia I, et al. Systemic effects of epidural and intra-articular glucocorticoid injections in diabetic and non-diabetic patients. Jt Bone Spine. 2007;74(5):472-6. https://doi.org/10.1016/j.jbspi n.2006.10.009.

13. Choudhry MN, Malik RA, Charalambous CP. Blood glucose levels following intra-articular steroid injections in patients with diabetes: a systematic review. JBJS Rev. 2016;4:3. https://doi. org/10.2106/jbjs.rvw.o.00029.

14. Maheu E, Rannou F, Reginster JY. Efficacy and safety of hyaluronic acid in the management of osteoarthritis: evidence from real-life setting trials and surveys. Semin Arthritis Rheum. 2016;45(4 Suppl):S28-33. https://doi.org/10.1016/j.semarthrit .2015.11.008. 
15. Cooper C, Rannou F, Richette P, Bruyere O, Al-Daghri N, Altman RD, et al. Use of intraarticular hyaluronic acid in the management of knee osteoarthritis in clinical practice. Arthritis Care Res (Hoboken). 2017;69(9):1287-96. https://doi.org/10.1002/ acr.23204

16. Bellamy N, Campbell J, Robinson V, Gee T, Bourne R, Wells G. Viscosupplementation for the treatment of osteoarthritis of the knee. Cochrane Database Syst Rev. 2006;2:CD005321. https:// doi.org/10.1002/14651858.cd005321.pub2.

17. Bannuru RR, Schmid CH, Kent DM, Vaysbrot EE, Wong JB, McAlindon TE. Comparative effectiveness of pharmacologic interventions for knee osteoarthritis: a systematic review and network meta-analysis. Ann Intern Med. 2015;162(1):46-54. https://doi.org/10.7326/M14-1231.

18. Bannuru RR, Natov NS, Obadan IE, Price LL, Schmid CH, McAlindon TE. Therapeutic trajectory of hyaluronic acid versus corticosteroids in the treatment of knee osteoarthritis: a systematic review and meta-analysis. Arthritis Rheum. 2009;61(12):1704-11. https://doi.org/10.1002/art.24925.

19. Bannuru RR, Natov NS, Dasi UR, Schmid CH, McAlindon TE. Therapeutic trajectory following intra-articular hyaluronic acid injection in knee osteoarthritis-meta-analysis. Osteoarthr Cartil. 2011;19(6):611-9. https://doi.org/10.1016/j.joca.2010.09.014.

20. Petrella RJ. Hyaluronic acid for the treatment of knee osteoarthritis: long-term outcomes from a naturalistic primary care experience. Am J Phys Med Rehabil. 2005;84(4):278-83.

21. Altman R, Fredericson M, Bhattacharyya SK, Bisson B, Abbott $\mathrm{T}$, Yadalam S, et al. Association between hyaluronic acid injections and time-to-total knee replacement surgery. J Knee Surg. 2016;29(7):564-70. https://doi.org/10.1055/s-0035-1568992.

22. Delbarre A, Amor B, Bardoulat I, Tetafort A, Pelletier-Fleury N. Do intra-articular hyaluronic acid injections delay total knee replacement in patients with osteoarthritis-a Cox model analysis. PLoS One. 2017;12(11):e0187227. https://doi.org/10.1371/ journal.pone.0187227.

23. McAlindon TE, Bannuru RR, Sullivan MC, Arden NK, Berenbaum F, Bierma-Zeinstra SM, et al. OARSI guidelines for the non-surgical management of knee osteoarthritis. Osteoarthr Cartil. 2014;22(3):363-88. https://doi.org/10.1016/j. joca.2014.01.003.

24. Hochberg MC, Altman RD, April KT, Benkhalti M, Guyatt G, McGowan J, et al. American College of Rheumatology 2012 recommendations for the use of nonpharmacologic and pharmacologic therapies in osteoarthritis of the hand, hip, and knee. Arthritis Care Res. 2012;64(4):465-74. https://doi.org/10.1002/ acr.21596.

25. NICE. Osteoarthritis care and management in adults: methods, evidence and recommendations. National Clinical Guideline Centre. London, UK: National Institute for Health and Care Excellence2014 February 2014. Report No.: CG177.

26. Jordan KM, Arden NK, Doherty M, Bannwarth B, Bijlsma JWJ, Dieppe P, et al. EULAR Recommendations 2003: an evidence based approach to the management of knee osteoarthritis: report of a Task Force of the Standing Committee for International Clinical Studies Including Therapeutic Trials (ESCISIT). Ann Rheum Dis. 2003;62(12):1145-55. https://doi.org/10.1136/ ard.2003.011742.

27. Jevsevar DS. Treatment of osteoarthritis of the knee: evidence-based guideline, 2nd edition. J Am Acad Orthop Surg. 2013;21(9):571-6. https://doi.org/10.5435/jaaos-21-09-571.

28. Trojian TH, Concoff AL, Joy SM, Hatzenbuehler JR, Saulsberry WJ, Coleman CI. AMSSM Scientific statement concerning viscosupplementation injections for knee osteoarthritis: importance for individual patient outcomes. Clin J Sport Med. 2016;26(1):111. https://doi.org/10.1097/JSM.0000000000000274.
29. Altman RD, Schemitsch E, Bedi A. Assessment of clinical practice guideline methodology for the treatment of knee osteoarthritis with intra-articular hyaluronic acid. Semin Arthritis Rheum. 2015;45(2):132-9. https://doi.org/10.1016/j.semarthrit 2015.04.013.

30. Wang CT, Lin J, Chang CJ, Lin YT, Hou SM. Therapeutic effects of hyaluronic acid on osteoarthritis of the knee. A metaanalysis of randomized controlled trials. J Bone Jt Surg Am. 2004;86-A(3):538-45.

31. Arrich J, Piribauer F, Mad P, Schmid D, Klaushofer K, Mullner M. Intra-articular hyaluronic acid for the treatment of osteoarthritis of the knee: systematic review and meta-analysis. CMAJ. 2005;172(8):1039-43. https://doi.org/10.1503/cmaj.1041203.

32. Medina JM, Thomas A, Denegar CR. Knee osteoarthritis: should your patient opt for hyaluronic acid injection? J Fam Pract. 2006;55(8):669-75.

33. Rutjes AW, Juni P, da Costa BR, Trelle S, Nuesch E, Reichenbach S. Viscosupplementation for osteoarthritis of the knee: a systematic review and meta-analysis. Ann Intern Med. 2012;157(3):180-91. https://doi.org/10.7326/0003-4819-1573-201208070-00473.

34. Miller LE, Block JE. US-approved intra-articular hyaluronic acid injections are safe and effective in patients with knee osteoarthritis: systematic review and meta-analysis of randomized, salinecontrolled trials. Clin Med Insights Arthritis Musculoskelet Disord. 2013;6:57-63. https://doi.org/10.4137/cmamd.s12743.

35. Strand V, McIntyre LF, Beach WR, Miller LE, Block JE. Safety and efficacy of US-approved viscosupplements for knee osteoarthritis: a systematic review and meta-analysis of randomized, saline-controlled trials. J Pain Res. 2015;8:217-28. https://doi. org/10.2147/JPR.S83076.

36. Bannuru RR, Osani M, Vaysbrot EE, McAlindon TE. Comparative safety profile of hyaluronic acid products for knee osteoarthritis: a systematic review and network meta-analysis. Osteoarthr Cartil. 2016;24(12):2022-41. https://doi.org/10.1016/j. joca.2016.07.010.

37. Bannuru RR, Brodie CR, Sullivan MC, McAlindon TE. Safety of repeated injections of sodium hyaluronate (SUPARTZ) for knee osteoarthritis: a systematic review and meta-analysis. Cartilage. 2016;7(4):322-32. https://doi.org/10.1177/1947603516642271.

38. Higgins JPT, Green S. Cochrane handbook for systematic reviews of interventions. Version 5.1.0 (updated March 2011). http:// www.handbook.cochrane.org The Cochrane Collaboration; 2011.

39. Moher D, Liberati A, Tetzlaff J, Altman DG, Group P. Preferred reporting items for systematic reviews and meta-analyses: the PRISMA statement. J Clin Epidemiol. 2009;62(10):1006-12. https://doi.org/10.1016/j.jclinepi.2009.06.005.

40. DerSimonian R, Laird N. Meta-analysis in clinical trials. Control Clin Trials. 1986;7(3):177-88.

41. Bradburn MJ, Deeks JJ, Berlin JA, Russell Localio A. Much ado about nothing: a comparison of the performance of metaanalytical methods with rare events. Stat Med. 2007;26(1):53-77. https://doi.org/10.1002/sim.2528.

42. Stijnen T, Hamza TH, Ozdemir P. Random effects meta-analysis of event outcome in the framework of the generalized linear mixed model with applications in sparse data. Stat Med. 2010;29(29):3046-67. https://doi.org/10.1002/sim.4040.

43. Normand SL. Meta-analysis: formulating, evaluating, combining, and reporting. Stat Med. 1999;18(3):321-59.

44. Higgins JP, Thompson SG, Deeks JJ, Altman DG. Measuring inconsistency in meta-analyses. BMJ. 2003;327(7414):557-60. https://doi.org/10.1136/bmj.327.7414.557.

45. Higgins JP, Thompson SG. Quantifying heterogeneity in a meta-analysis. Stat Med. 2002;21(11):1539-58. https://doi. org/10.1002/sim.1186. 
46. Harbord RM, Egger M, Sterne JA. A modified test for smallstudy effects in meta-analyses of controlled trials with binary endpoints. Stat Med. 2006;25(20):3443-57. https://doi. org/10.1002/sim.2380.

47. Sterne JA, Sutton AJ, Ioannidis JP, Terrin N, Jones DR, Lau J, et al. Recommendations for examining and interpreting funnel plot asymmetry in meta-analyses of randomised controlled trials. BMJ. 2011;343:d4002. https://doi.org/10.1136/bmj.d4002.

48. Egger M, Davey Smith G, Schneider M, Minder C. Bias in meta-analysis detected by a simple, graphical test. BMJ. 1997;315(7109):629-34.

49. Guyatt G, Oxman AD, Akl EA, Kunz R, Vist G, Brozek $\mathrm{J}$, et al. GRADE guidelines: 1. Introduction-GRADE evidence profiles and summary of findings tables. J Clin Epidemiol. 2011;64(4):383-94. https://doi.org/10.1016/j.jclin epi.2010.04.026.

50. GRADEpro GDT: GRADEpro Guideline Development Tool [Software]. McMaster University, 2015 (developed by Evidence Prime, Inc.). http://gradepro.org.. Evidence Prime, Inc.

51. Altman RD, Moskowitz R. Intraarticular sodium hyaluronate (Hyalgan) in the treatment of patients with osteoarthritis of the knee: a randomized clinical trial. Hyalgan Study Group. J Rheumatol. 1998;25(11):2203-12.

52. Altman RD, Akermark C, Beaulieu AD, Schnitzer T, Durolane International Study G. Efficacy and safety of a single intra-articular injection of non-animal stabilized hyaluronic acid (NASHA) in patients with osteoarthritis of the knee. Osteoarthr Cartil. 2004;12(8):642-9.

53. Arden NK, Akermark C, Andersson M, Todman MG, Altman RD. A randomized saline-controlled trial of NASHA hyaluronic acid for knee osteoarthritis. Curr Med Res Opin. 2014;30(2):279-86.

54. Baltzer AWA, Moser C, Jansen SA, Krauspe R. Autologous conditioned serum (Orthokine) is an effective treatment for knee osteoarthritis. Osteoarthr Cartil. 2009;17(2):152-60.

55. Brandt KD, Block JA, Michalski JP, Moreland LW, Caldwell JR, Lavin PT. Efficacy and safety of intra-articular sodium hyaluronate in knee osteoarthritis. Clin Orthop Relat Res. 2001;385:130.

56. Carrabba M, Paresce E, Angelini M, Re KA, Torchiana EEM, Perbellini A. The safety and efficacy of different dose schedules of hyaluronic acid in the treatment of painful osteoarthritis of the knee with joint effusion. Eur J Rheumatol Inflamm. 1995;15(1):25.

57. Cohen MM, Altman RD, Hollstrom R, Hollstrom C, Sun C, Gipson B. Safety and efficacy of intra-articular sodium hyaluronate (Hyalgan) in a randomized, double-blind study for osteoarthritis of the ankle. Foot Ankle Int. 2008;29(7):657-63.

58. DeCaria JE, Montero-Odasso M, Wolfe D, Chesworth BM, Petrella RJ. The effect of intra-articular hyaluronic acid treatment on gait velocity in older knee osteoarthritis patients: a randomized, controlled study. Arch Gerontol Geriatr. 2012;55(2):310-5.

59. DeGroot H 3rd, Uzunishvili S, Weir R, Al-omari A, Gomes B. Intra-articular injection of hyaluronic acid is not superior to saline solution injection for ankle arthritis: a randomized, double-blind, placebo-controlled study. J Bone Jt Surg Am. 2012;94(1):2-8.

60. Diracoglu D, Vural M, Baskent A, Dikici F, Aksoy C. The effect of viscosupplementation on neuromuscular control of the knee in patients with osteoarthritis. J Back Musculoskelet Rehabil. 2009;22(1):1-9.

61. Dixon AS, Jacoby RK, Berry H, Hamilton EB. Clinical trial of intra-articular injection of sodium hyaluronate in patients with osteoarthritis of the knee. Curr Med Res Opin. 1988;11(4):205-13.

62. Gormeli G, Gormeli CA, Ataoglu B, Colak C, Aslanturk O, Ertem K. Multiple PRP injections are more effective than single injections and hyaluronic acid in knees with early osteoarthritis: a randomized, double-blind, placebo-controlled trial. Knee Surg Sports Traumatol Arthrosc. 2017;25(3):958-65.

63. Hangody L, Szody R, Lukasik P, Zgadzaj W, Lenart E, Dokoupilova $\mathrm{E}$, et al. Intraarticular injection of a cross-linked sodium hyaluronate combined with triamcinolone hexacetonide (Cingal) to provide symptomatic relief of osteoarthritis of the knee: a randomized, double-blind, placebo-controlled multicenter clinical trial. Cartilage. 2017;101518378:1947603517703732.

64. Huang T-L, Chang C-C, Lee C-H, Chen S-C, Lai C-H, Tsai C-L. Intra-articular injections of sodium hyaluronate (Hyalgan) in osteoarthritis of the knee: a randomized, controlled, doubleblind, multicenter trial in the Asian population. BMC Musculoskelet Disord. 2011;12(100968565):221

65. Jorgensen A, Stengaard-Pedersen K, Simonsen O, Pfeiffer-Jensen $\mathrm{M}$, Eriksen $\mathrm{C}$, Bliddal $\mathrm{H}$, et al. Intra-articular hyaluronan is without clinical effect in knee osteoarthritis: a multicentre, randomised, placebo-controlled, double-blind study of 337 patients followed for 1 year. Ann Rheum Dis. 2010;69(6):1097-102.

66. Karlsson J, Sjogren LS, Lohmander LS. Comparison of two hyaluronan drugs and placebo in patients with knee osteoarthritis. A controlled, randomized, double-blind, parallel-design multicentre study. Rheumatology (Oxford, England). 2002;41(11):1240-8.

67. Kotevoglu N, Iyibozkurt PC, Hiz O, Toktas H, Kuran B. A prospective randomised controlled clinical trial comparing the efficacy of different molecular weight hyaluronan solutions in the treatment of knee osteoarthritis. Rheumatol Int. 2006;26(4):325-30.

68. Kul-Panza E, Berker N. Is hyaluronate sodium effective in the management of knee osteoarthritis? A placebo-controlled double-blind study. Miner Med. 2010;101(2):63-72.

69. Petrella RJ, DiSilvestro MD, Hildebrand C. Effects of hyaluronate sodium on pain and physical functioning in osteoarthritis of the knee: a randomized, double-blind, placebo-controlled clinical trial. Arch Intern Med. 2002;162(3):292-8.

70. Puhl W, Bernau A, Greiling H, Kopcke W, Pforringer W, Steck $\mathrm{KJ}$, et al. Intra-articular sodium hyaluronate in osteoarthritis of the knee: a multicenter, double-blind study. Osteoarthr Cartil. 1993;1(4):233-41.

71. Salk RS, Chang TJ, D'Costa WF, Soomekh DJ, Grogan KA. Sodium hyaluronate in the treatment of osteoarthritis of the ankle: a controlled, randomized, double-blind pilot study. J Bone Jt Surg Am. 2006;88(2):295-302.

72. van der Weegen W, Wullems JA, Bos E, Noten H, van Drumpt RA. No difference between intra-articular injection of hyaluronic acid and placebo for mild to moderate knee osteoarthritis: a randomized, controlled, double-blind trial. J Arthroplasty. 2015;30(5):754-7. https://doi.org/10.1016/j.arth.2014.12.012.

73. Altman RD, Rosen JE, Bloch DA, Hatoum HT, Korner P. A double-blind, randomized, saline-controlled study of the efficacy and safety of EUFLEXXA for treatment of painful osteoarthritis of the knee, with an open-label safety extension (the FLEXX trial). Semin Arthritis Rheum. 2009;39(1):1-9.

74. Atchia I, Kane D, Reed MR, Isaacs JD, Birrell F. Efficacy of a single ultrasound-guided injection for the treatment of hip osteoarthritis. Ann Rheum Dis. 2011;70(1):110-6.

75. Chevalier X, Jerosch J, Goupille P, van Dijk N, Luyten FP, Scott DL, et al. Single, intra-articular treatment with $6 \mathrm{ml}$ hylan G-F 20 in patients with symptomatic primary osteoarthritis of the knee: a randomised, multicentre, double-blind, placebo controlled trial. Ann Rheum Dis. 2010;69(1):113-9.

76. Day R, Brooks P, Conaghan PG, Petersen M, Multicenter Trial Group. A double blind, randomized, multicenter, parallel group study of the effectiveness and tolerance of intraarticular hyaluronan in osteoarthritis of the knee. J Rheumatol. 2004;31(4):775-82. 
77. Dougados M, Nguyen M, Listrat V, Amor B. High molecular weight sodium hyaluronate (hyalectin) in osteoarthritis of the knee: a 1 year placebo-controlled trial. Osteoarthr Cartil. 1993;1(2):97-103.

78. Henderson EB, Smith EC, Pegley F, Blake DR. Intra-articular injections of $750 \mathrm{kD}$ hyaluronan in the treatment of osteoarthritis: a randomised single centre double-blind placebo-controlled trial of 91 patients demonstrating lack of efficacy. Ann Rheum Dis. 1994;53(8):529-34.

79. Henrotin Y, Berenbaum F, Chevalier X, Marty M, Richette P, Rannou F. Reduction of the serum levels of a specific biomarker of cartilage degradation (Coll2-1) by hyaluronic acid (KARTILAGE CROSS) compared to placebo in painful knee osteoarthritis patients: the EPIKART Study, a pilot prospective comparative randomized double blind trial. BMC Musculoskelet Disord. 2017;18(1):222.

80. Heyworth BE, Lee JH, Kim PD, Lipton CB, Strauch RJ, Rosenwasser MP. Hylan versus corticosteroid versus placebo for treatment of basal joint arthritis: a prospective, randomized, doubleblinded clinical trial. J Hand Surg. 2008;33(1):40-8.

81. Huskisson EC, Donnelly S. Hyaluronic acid in the treatment of osteoarthritis of the knee. Rheumatology (Oxford, England). 1999;38(7):602-7.

82. Jubb RW, Piva S, Beinat L, Dacre J, Gishen P. A one-year, randomised, placebo (saline) controlled clinical trial of 500-730 kDa sodium hyaluronate (Hyalgan) on the radiological change in osteoarthritis of the knee. Int J Clin Pract. 2003;57(6):467-74.

83. Kwon YW, Eisenberg G, Zuckerman JD. Sodium hyaluronate for the treatment of chronic shoulder pain associated with glenohumeral osteoarthritis: a multicenter, randomized, double-blind, placebo-controlled trial. J Shoulder Elbow Surg. 2013;22(5):584-94.

84. Lohmander LS, Dalen N, Englund G, Hamalainen M, Jensen $\mathrm{EM}, \mathrm{Karlsson} \mathrm{K}$, et al. Intra-articular hyaluronan injections in the treatment of osteoarthritis of the knee: a randomised, double blind, placebo controlled multicentre trial. Hyaluronan Multicentre Trial Group. Ann Rheum Dis. 1996;55(7):424-31.

85. Lundsgaard C, Dufour N, Fallentin E, Winkel P, Gluud C. Intra-articular sodium hyaluronate $2 \mathrm{~mL}$ versus physiological saline $20 \mathrm{~mL}$ versus physiological saline $2 \mathrm{~mL}$ for painful knee osteoarthritis: a randomized clinical trial. Scand J Rheumatol. 2008;37(2):142-50.

86. Munteanu SE, Zammit GV, Menz HB, Landorf KB, Handley CJ, Elzarka A, et al. Effectiveness of intra-articular hyaluronan (Synvisc, hylan G-F 20) for the treatment of first metatarsophalangeal joint osteoarthritis: a randomised placebo-controlled trial. Ann Rheum Dis. 2011;70(10):1838-41.

87. Navarro-Sarabia F, Coronel P, Collantes E, Navarro FJ, de la Serna AR, Naranjo A, et al. A 40-month multicentre, randomised placebo-controlled study to assess the efficacy and carry-over effect of repeated intra-articular injections of hyaluronic acid in knee osteoarthritis: the AMELIA project. Ann Rheum Dis. 2011;70(11):1957-62. https://doi.org/10.1136/ ard.2011.152017.
88. Petrella RJ, Cogliano A, Decaria J. Combining two hyaluronic acids in osteoarthritis of the knee: a randomized, double-blind, placebo-controlled trial. Clin Rheumatol. 2008;27(8):975-81.

89. Pham T, Le Henanff A, Ravaud P, Dieppe P, Paolozzi L, Dougados M. Evaluation of the symptomatic and structural efficacy of a new hyaluronic acid compound, NRD101, in comparison with diacerein and placebo in a 1 year randomised controlled study in symptomatic knee osteoarthritis. Ann Rheum Dis. 2004;63(12):1611-7.

90. Qvistgaard E, Christensen R, Torp-Pedersen S, Bliddal H. Intraarticular treatment of hip osteoarthritis: a randomized trial of hyaluronic acid, corticosteroid, and isotonic saline. Osteoarthr Cartil. 2006;14(2):163-70.

91. Richette P, Ravaud P, Conrozier T, Euller-Ziegler L, Mazieres B, Maugars Y, et al. Effect of hyaluronic acid in symptomatic hip osteoarthritis: a multicenter, randomized, placebo-controlled trial. Arthritis Rheum. 2009;60(3):824-30.

92. Strand V, Baraf HS, Lavin PT, Lim S, Hosokawa H. A multicenter, randomized controlled trial comparing a single intraarticular injection of Gel-200, a new cross-linked formulation of hyaluronic acid, to phosphate buffered saline for treatment of osteoarthritis of the knee. Osteoarthr Cartil. 2012;20(5):350-6. https://doi.org/10.1016/j.joca.2012.01.013.

93. Wobig M, Dickhut A, Maier R, Vetter G. Viscosupplementation with hylan G-F 20: a 26-week controlled trial of efficacy and safety in the osteoarthritic knee. Clin Ther. 1998;20(3):410-23.

94. Chou R, McDonagh MS, Nakamoto E, Griffin J. Analgesics for osteoarthritis: an update of the 2006 Comparative Effectiveness Review. Comparative Effectiveness Review No. 38. October 2011. AHRQ Publication No. 11(12)-EHC076-EF. Rockville, MD: Agency for Healthcare Research and Quality. https://effec tivehealthcare.ahrq.gov/topics/osteoarthritis-pain/research. Accessed 27 Apr 2018.

95. McAlindon TE, Bannuru RR. Osteoarthritis: is viscosupplementation really so unsafe for knee OA? Nat Rev Rheumatol. 2012;8(11):635-6. https://doi.org/10.1038/nrrheum.2012.152.

96. Cutolo M, Berenbaum F, Hochberg M, Punzi L, Reginster JY. Commentary on recent therapeutic guidelines for osteoarthritis. Semin Arthritis Rheum. 2014;44(6):611-7. https://doi. org/10.1016/j.semarthrit.2014.12.003.

97. Cermelli C, Cuoghi A, Scuri M, Bettua C, Neglia RG, Ardizzoni $\mathrm{A}$, et al. In vitro evaluation of antiviral and virucidal activity of a high molecular weight hyaluronic acid. Virol J. 2011;8:141. https ://doi.org/10.1186/1743-422X-8-141.

98. Pirnazar P, Wolinsky L, Nachnani S, Haake S, Pilloni A, Bernard GW. Bacteriostatic effects of hyaluronic acid. J Periodontol. 1999;70(4):370-4. https://doi.org/10.1902/jop.1999.70.4.370.

99. Leopold SS, Warme WJ, Pettis PD, Shott S. Increased frequency of acute local reaction to intra-articular hylan GF-20 (Synvisc) in patients receiving more than one course of treatment. J Bone Jt Surg Am. 2002;84-A(9):1619-23.

100. Pagnano M, Westrich G. Successful nonoperative management of chronic osteoarthritis pain of the knee: safety and efficacy of retreatment with intra-articular hyaluronans. Osteoarthr Cartil. 2005;13(9):751-61. https://doi.org/10.1016/j.joca.2005.04.012. 


\section{Affiliations}

\section{Germain Honvo $^{1,2}\left(\mathbb{D} \cdot\right.$ Jean-Yves Reginster ${ }^{1,2,3}$ (D) Francois Rannou $^{4,5} \cdot$ Xavier Rygaert $^{1,2} \cdot$ Anton Geerinck $^{1,2}$. Véronique Rabenda ${ }^{1,2} \cdot$ Tim McAlindon $^{6} \cdot$ Alexia Charles $^{1,2} \cdot$ Nicholas Fuggle $^{7}$. Cyrus Cooper ${ }^{2,7,8}$. Elizabeth Curtis ${ }^{7}$. Nigel Arden ${ }^{7,9} \cdot$ Bernard Avouac $^{1} \cdot$ Olivier Bruyère $^{1,2}(0$}

\author{
Germain Honvo \\ germain.honvo@uliege.be \\ Jean-Yves Reginster \\ jyreginster@uliege.be \\ Francois Rannou \\ francois.rannou@aphp.fr \\ Xavier Rygaert \\ xavier.rygaert@student.uliege.be \\ Anton Geerinck \\ anton.geerinck@uliege.be \\ Véronique Rabenda \\ veronique.rabenda@uliege.be \\ Tim McAlindon \\ tmcalindon@tuftsmedicalcenter.org \\ Alexia Charles \\ alexia.charles@uliege.be \\ Nicholas Fuggle \\ nrf@mrc.soton.ac.uk \\ Cyrus Cooper \\ bc@mrc.soton.ac.uk \\ Elizabeth Curtis \\ cc@mrc.soton.ac.uk \\ Nigel Arden \\ nigel.arden@ndorms.ox.ac.uk
}

Bernard Avouac

bernardavouac@sfr.fr

Olivier Bruyère

olivier.bruyere@uliege.be

1 Department of Public Health, Epidemiology and Health Economics, University of Liège, Liège, Belgium

2 WHO Collaborating Centre for Public Heath Aspects of Musculoskeletal Health and Aging, Liège, Belgium

3 Biochemistry Department, College of Science, King Saud University, Riyadh, Kingdom of Saudi Arabia

4 Division of Physical Medicine and Rehabilitation, Department of Rheumatology, AP-HP Cochin Hospital, Université Paris Descartes Sorbonne Paris Cité, Paris, France

5 INSERM U1124, Paris, France

6 Division of Rheumatology, Tufts Medical Center, Boston, MA, USA

7 MRC Lifecourse Epidemiology Unit, University of Southampton, Southampton General Hospital, Southampton, UK

8 National Institute for Health Research (NIHR), Musculoskeletal Biomedical Research Unit, University of Oxford, Oxford, UK

9 Arthritis Research UK Centre for Sport, Exercise and Osteoarthritis, University of Oxford, Oxford, UK 